\title{
CONSUMERS PURCHASE BEHAVIOR TOWARD ECO-LABELLING
}

\author{
by \\ Madiha Tahir \\ MA, Fashion, Ryerson University, 2017
}

\author{
A MRP \\ presented to Ryerson University \\ in partial fulfillment of the \\ requirements for the degree of \\ Master of Arts \\ In the Program of \\ Fashion
}

Toronto, Ontario, Canada, 2017

(C) Madiha Tahir 2017 


\section{Author's Declaration for Electronic Submission of a MRP}

I hereby declare that I am the sole author of this MRP. This is a true copy of the MRP, including any required final revisions.

I authorize Ryerson University to lend this MRP to other institutions or individuals for the purpose of scholarly research.

I further authorize Ryerson University to reproduce this MRP by photocopying or by other means, in total or in part, at the request of other institutions or individuals for the purpose of scholarly research.

I understand that my MRP may be made electronically available to the public. 


\title{
CONSUMERS PURCHASE BEHAVIOR TOWARD ECO-LABELLING
}

\author{
Madiha Tahir \\ Master of Arts in fashion \\ Ryerson University, 2017
}

\begin{abstract}
The primary goal of Eco-labels is to promote the knowledge of consumers about positive environmental effects of products and to guide them toward purchasing environmental friendly products. The purpose of the study is to understand fashion consumers' purchasing behavior toward eco-labelling with respect to four factors: the current fashion system, environmental responsibility, ethical responsibility, and social responsibility. The relationship between these four factors in conjunction with eco-labelling and purchase behavior was tested and analyzed. The results proved that eco-labels did influence consumers' buying behavior. Eco-label help consumers to make their decision faster, distinguish those products that they want to buy from the other ordinary products.
\end{abstract}




\section{Acknowledgements}

The immense task of completing the MRP could not have been successfully completed without the unyielding support of my supervisor Osmud Rahman whose great insights, guidance, support and patience enabled me to develop a comprehensive understanding on the topic. I would also

like to thank Grahame Lynch, Alison Matthews David, and Kimberly Wahl for their support in the completion of this overarching task.

I would also like to announce my sincerest gratitude for the unbound help and support of my family members and friends. 


\section{Table of Content}

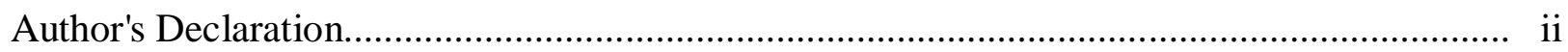

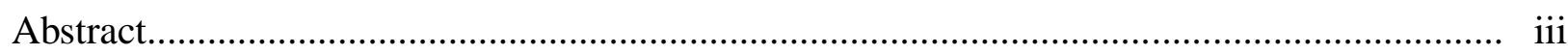

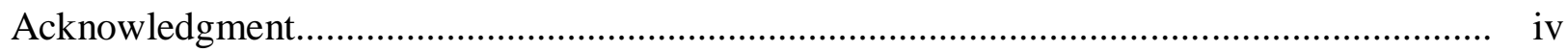

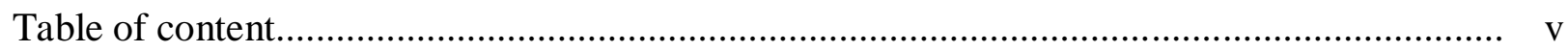

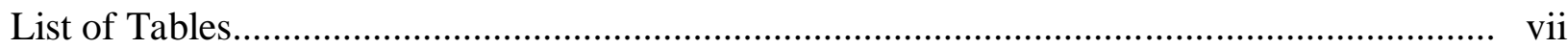

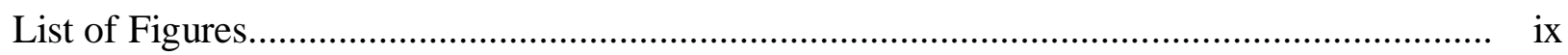

List of Appendix..................................................................................................

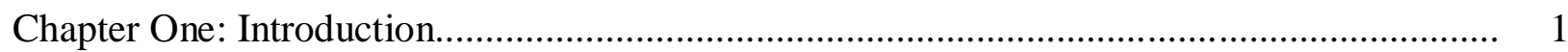

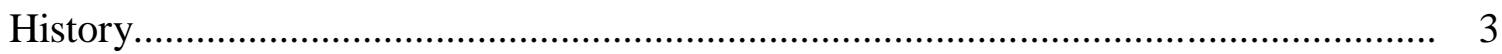

Eco-labelling...................................................................................................

Environmental Responsibility.............................................................................. 5

Ethical Responsibility......................................................................................... 6

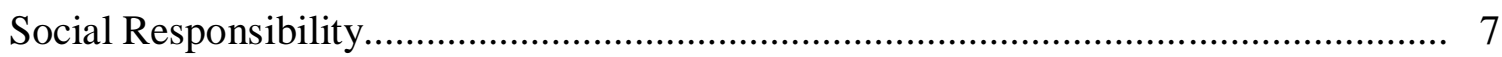

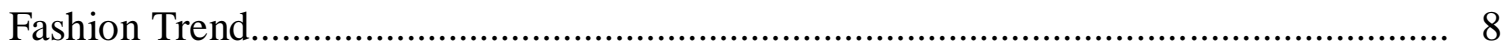

Chapter Two: Literature Review............................................................................... 10

Chapter Three: Methodology...................................................................................... 28

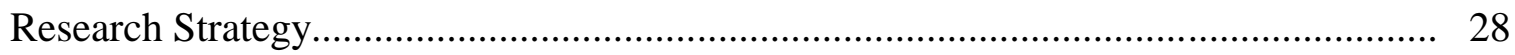

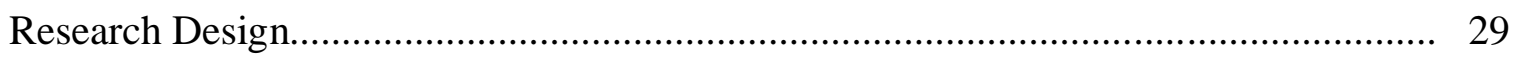

Convenience sampling ...................................................................................... 31

Self-complete questionnaire................................................................................ 31

Recruitment Method........................................................................................... 33

Ethical Consideration........................................................................................... 35

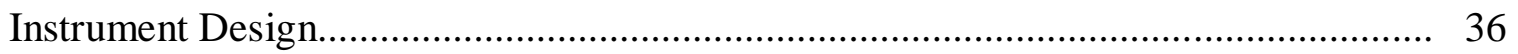

Sample 
Questionnaire Design........................................................................ 37

Analytical Methods............................................................................... 38

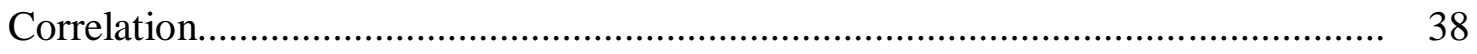

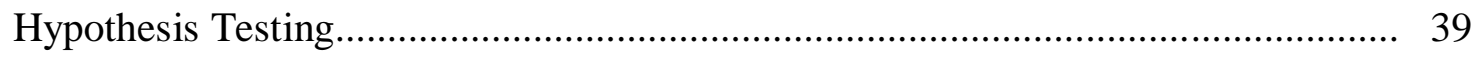

Chapter Four: Findings and analysis............................................................... 41

Variables and consistency...................................................................... 41

Demographic Profile............................................................................... 43

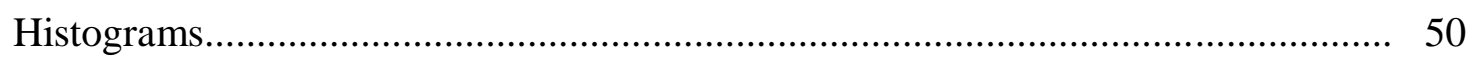

Hypothesis Testing.............................................................................. 54

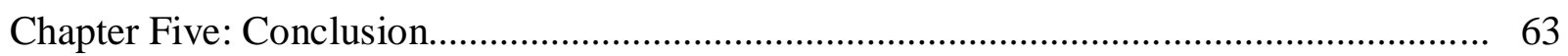

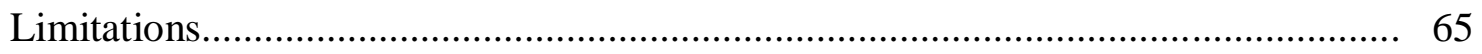

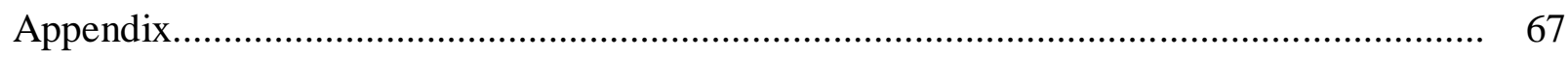

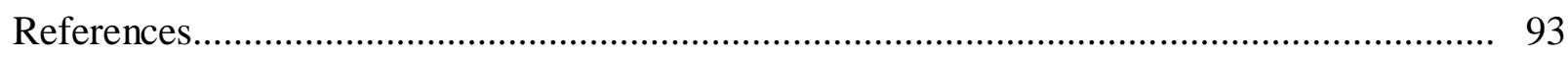




\section{List of Tables}

Table 1. Cronbach's Alpha for Each Variable..................................................................42

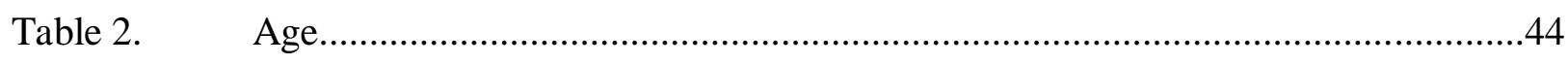

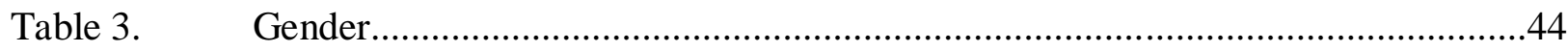

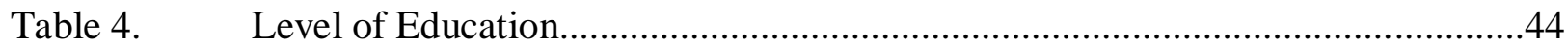

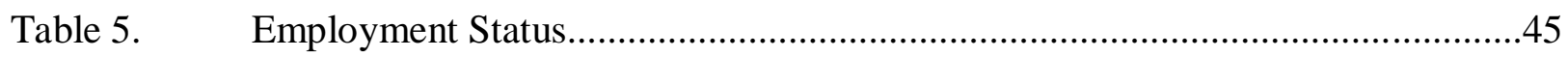

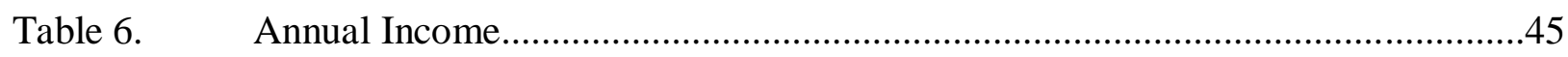

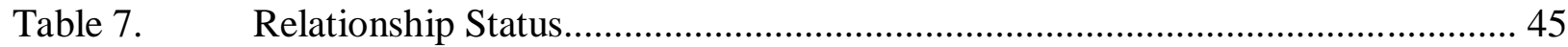

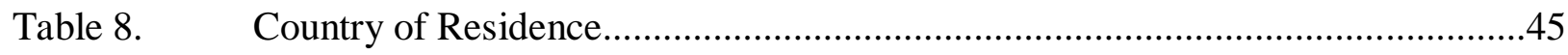

Table 9. Awareness of Common Textile Eco-Labels..........................................................46

Table 10. Annual Expenditure on Clothing........................................................................46

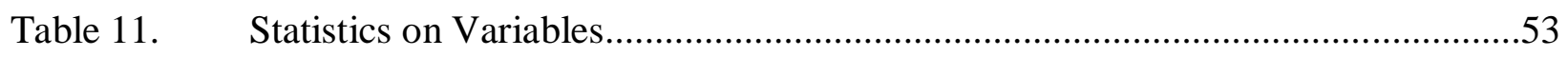

Table 12. Correlation between Purchasing Behavior and Importance of Certification, Involvement in Certification, Willingness to Pay, and Commitment toward Ecolabels

Table 13. Regression Model: Purchasing Behavior According to Involvement in Certification, Importance of Certification, Commitment toward Eco-labels, Willingness to Pay Combined.

Table 14. Beta Coefficients of the Regression Model: Purchase Behavior According to Involvement in Certification and Importance of Certification Commitment Toward Eco-labels, Willingness to Pay. .56

Table15: Variation in Purchasing Behavior Explained by the Regression Model................56

Table 16: Correlation Between Eco-Labelling and Environmental Responsibility, Social Responsibility, Ethical Responsibility

Table17. Regression Model: Eco-labelling According to Environmental Responsibility, Social Responsibility, and Ethical Responsibility. 
Table 18: Beta Coefficients of the Regression Model: Eco-lebelling According to Environmental Responsibility, Social Responsibility, and Ethical Responsibility

Table19. Variation in Eco-Labelling Explained by the Regression Model..........................59

Table20: Correlation between Purchasing Behavior and Environmental Responsibility, Social Responsibility, Ethical Responsibility, and Fashion Trends........................60

Table 21. Regression Model: Purchasing Behavior According to Environmental Responsibility, Social Responsibility, Ethical Responsibility, and Fashion

Trends .61

Table 22. Beta Coefficients of the Regression Model: Purchasing Behavior According to Environmental Responsibility, Social Responsibility, Ethical Responsibility, and Fashion Trends. 61

Table 23. Variation in Purchasing Behavior Explained by the Regression Model. .62 


\section{List of Figures}

Figure 1. Income and Willingness to Buy Eco-Label Products.....................................47

Figure 2. Age and Willingness to Buy Eco-Label Products..........................................48

Figure 3. Education and Willingness to Buy Eco-Label Products.................................49

Figure 4. Impact of Ethical Responsibility........................................................50

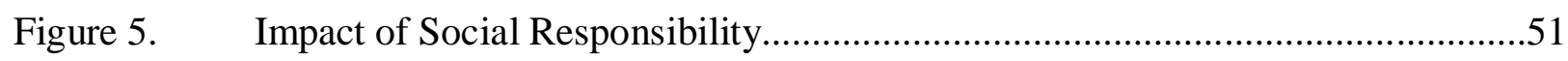

Figure 6. Impact of Environmental Responsibility..............................................51

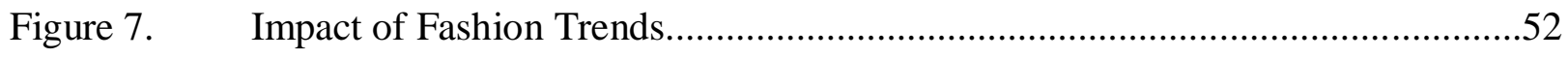




\section{List of Appendix}

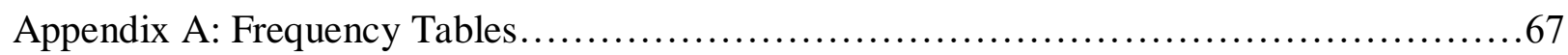

Frequency Table of Fashion Trend...............................................67

Frequency Table of Ethical Responsibility ......................................68

Frequency Table of Social Responsibility .........................................69

Frequency Table of Environmental Responsibility...............................70

Appendix B: Eco-friendly Fashion Related Products Images............................... 73

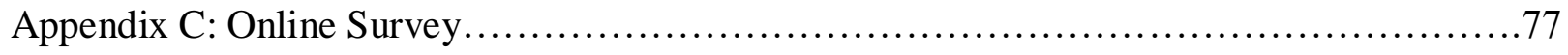

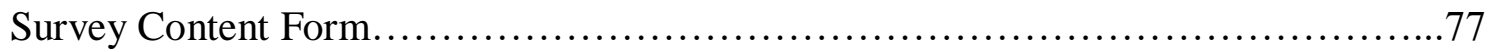

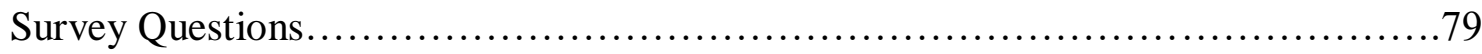

Ethics Approval Letter........................................................ 


\section{Chapter One}

\section{Introduction}

\section{Introduction}

Rapid economic development in previous years has increased consumerism worldwide, causing ecological decay through over-consumption and use of natural resources (Chen et al. 2010). It is anticipated that if current patterns of economic development and irresponsible consumption patterns continue, ecological decline would increase with the consequences of global warming, diminution of the stratospheric ozone layer, noise and light pollution, contamination of oceans, lakes and streams, and corrosive rain and desertification (Ramlogan 1997). Therefore, on a worldwide scale, there is an increased awareness and concern for global warming and unfavorable climate conditions caused by the fashion industry. These are a few of the reasons why people now show interest towards environmental protection and sustainable development. A general decay in the physical landscape is driving people and corporations to advocate and execute changes for enhancing the present condition of the environment. A shift towards more ecological consumption patterns is required and is crucial to increase individuals' environmental awareness and consciousness. Individuals can reduce their effect on the environment by reevaluating their purchasing behavior. The belief is that the consumers' pro-environmental concern is one of the determinants of their "green purchasing" behavior. Purchasing and consuming ecological items could be beneficial to the environment (Mainieri et al. 1997).

As indicated by Dagens Industri (DI, 2009), despite the fact that ecological products have a small share in the market, the sale of organic products is rising. Organizations are starting to utilize environmental strategies and manufacture environmentally-friendly products, aimed at having a positive effect on people and environment to advance companies' reputations in the 
market (Esty and Winston 2009, pp. 3, 13). Although the market share of environmentally-friendly products is not immense, recent years witnessed a steady growth in the demand on these kinds of products. A lot of organizations from different industries have offered ecological products: from food (ecological milk from Arla) to cars (Miljötaxi in Stockholm) to fashion brands (H\&M, Nike, Mark and Spencer). Some other examples of ecological products are recyclable and reusable packaging, nonpolluting products, energy efficient light bulbs, organic cotton etc. (Mainieri et al. 2001).

Companies put special eco-labels on products in order to distinguish eco-friendly products from ordinary ones (Gallastegui 2002, p. 316; Teisl et al. 2001, p. 339). An eco-label is a label or logo to confirm that a product meets high environmental and performance standards and has less effect on the environment than non-labeled items. Beyond this environmental aspect, it demonstrates that an organization is socially responsible (Ghauri and Cateora 2005, p. 475). One of the first ecological labels was the EU Ecolable. It was established in 1992 to convince organizations to deliver products and services which are environmentally friendly. These labels convey important product information to customers. However, sometimes consumers have to pay more for the products that carry an eco-label sign. (Vitalis 2002, p. 7)

From the consumers' point of view, eco-labels can be used as tools or indicators to enhance consumers' decision-making with regards to the values and significance of environmentallyfriendly products. It is vital to raise environmental awareness and consciousness. Eco-labels are an effective approach to teaching customers about environmentally-friendly products. Over the last three decades, a growing number of ecological labels have been created by different organizations, industrial sectors and non-government associations (NGOs), and national or universal administrative associations (Environmental Potential Agency). In order to achieve 
educational goals, the increasing popularity of these labels must be found in conjunction with the advantages they convey to organizations and purchasers. From the customer's perspective, the labeling will decrease instability about the environmental performance of items and empower buyers to pick items that cause less harm to the environment (Porter 2005).

Consumer buying behavior can be defined as the analysis of how independent consumers or groups purchase, use and regulate services according to their needs and preferences. These needs vary in different cultures, contexts and on an individual basis (Kotler et al. 2009, p. 224). New eco-labelling plans are being included each year by various associations, from non-benefit organizations to for profit retailers (Saunders 2010). However, with such a large number of contending eco-labels accessible today, questions arise as to how well consumers understand and trust these eco-labels. Do increasing quantities of eco-labels bring certainty or doubt to buyers and consumers?

\section{History}

Concerns for environmentally friendly consumption are not new. Ideas can be traced back to the late 1960s (D'Souza et al. 2006a) when it was recognized that increases in hazard production systems were the cause of damaging the environment. To move towards more sustainable and environmentally friendly approaches, several attempts have been made by conscious organizations. A flash of interest in eco-labels also surfaced in the 1980s and early 1990s when there was a shift from government-controlled measures to a more market regulated, environmental policy that included eco-labeling (Jordan et al. 2004). Heightened interest in environmental issues over recent years has promoted sustainable consumption and environmental labeling in an effort to enable consumers to differentiate between environmentally friendly and non-environmentally 
friendly products. Such actions assume that if consumers are presented with appropriate label information, their purchases will change and subsequently it will improve sustainable practice and consumption (Horne 2007).

\section{Eco-labelling}

The term "Eco-labelling" has turned into a trendy expression in today's supportable business world. The utilization of eco-labelling in different industries has been expanding, in some cases as an environmental requirement and in others just as a marketing tool. Questions emerge about how well these eco-labels are valued and comprehended by customers. On a worldwide level, there is an increased awareness and concern of global warming and unfavorable climate conditions. Subsequently, there is a spur of interest towards developing environmental security and economic improvement. Consumers can lessen harmful effects on the environment through their purchasing choices and consumption. The rising number of potential buyers of eco-friendly items are opening doors for organizations to develop and utilize the 'eco-friendly' or 'ecologically friendly' as a market segment of their offers (Moon et al. 2002).

Eco-labels are considered kind of "new" instruments focusing on specific information about environmental effects related to distributing, producing, consuming and/or disposing of product. There are different forms of eco-labels, some are mandatory and some are voluntary. Mandatory labels generally referred to certain product standards established by the government and written in the law. Voluntary labels can be divided into three categories according to the ISO (International Standard Organization): Type I, Type II and Type III.

The first type of eco-label refers exactly to the environmental quality of a product; it tries to convince people to purchase environmentally friendly goods (Gallastegui 2002, p. 317). This 
type of label is mostly known by customers and commonly referred to as eco-label (Rex and Bauman 2006, p. 570).

Type II is labels made by the manufacturer of the product, importers or distributors. They concern specific qualities of the product, such as CFC-free products (free of chlorofluorocarbons, which are harmful chemicals that destroy the ozone) or ICA Ekologiskt.

Type III labels give measured ecological information of a product, which is based upon independent verification using preset parameters. These parameters are set by qualified independent bodies and based on life cycle assessment. This type of information provided by the label is similar to nutrition labels on food products that detail fat, sugar or vitamin contents. It is a rare label. (Ecospecifier 2010; Gallastegui 2002, p. 316).

Since this research concerns customer perception of eco-labels, it will concentrate on ecolabel type I, as it is the most common type found on garments. It also focuses on customer attention on overall environmental characteristics of the product.

\section{Environmental Responsibility}

Currently, the idea of environmentally friendly production is almost pervasive by showing application in corporate strategy, customer choice, student education and scholarly research. The need for sustainable business practices by organizations around the world is recognized to be a result of the overall increment in consumer awareness about environmental protection and social inequities. Over the last decade, environment safety has become a vital aspect because of the increasing number of environmental issues identified with acid rains, depletion of the ozone layer, degradation of the land, and many other ecological issues. These issues of environmental change have raised the consumers' concern and awareness about the environment around the world, and 
also the sustainable practice and consumption of environmentally friendly products in different countries (Doyle, 1992; Vandermerwe and Oliff, 1990).

The aim or rationale behind the implementation of eco-labels is to make it practical for purchasers to recognize items that are less harmful to the earth from other products. Moreover, consumer desire for eco-labelled items could put pressure on makers of moderately environmentally friendly items to continuously remove harmful chemicals and or processes out of the market. As a result, it could motivate organizations to extend their business toward producing more environmentally beneficial items (Thøgersen, 2002).

There has been an adjustment in customer attitude towards a greener way of life. Many individuals are willing to reduce harmful effects on the earth through their purchasing behavior. Businesses and organizations have observed this changing attitude of consumers, and they are attempting to capitalize in today's competitive market by exploiting the potential in the green market industry.

\section{Ethical Responsibility}

A growing number of individuals reevaluate their consumption choices in light of ethical values. For example, environmentally friendly products, sustainable production techniques, ethical working guidelines (fair wages and working conditions), and human rights are few considerations

consumers take into account before making purchases. Consumers are becoming progressively aware of the material substance of their clothing purchases. Some are even searching and examining material suppliers, demanding and putting pressure on-fashion supply networks to be more transparent and ethical. 
Ethical fashion is characterized as fashion clothing that is delivered under reasonable exchange standards in sweatshop-free labor conditions, with attempts made to lessen the environmental destructiveness of the production procedure (Joergens, 2006). This term may also be described as fashion awareness and sensitivity as it concerns work conditions and the environment. Fashion organizations frequently consider the following significant aspects of ethical fashion: picking environmental friendly items and employing sourcing and production strategies consistent with the direction of reasonable exchange (Joergens, 2006).

Ethical consumerism and corporate, social and environmental responsibility will assume critical parts in accomplishing a practical and safe fashion industry. The connection among learning and support has turned out to be the most vital part of developing sustainable organizations. Future research ought to investigate the effects of ethical fashion supply chains on consumer behavior. Absence of information to consumers is a primary obstacle in the way of ethical buying, which should be addressed.

\section{Social Responsibility}

Consumers initially need to become aware of an association's level of social responsibility before this component can affect their purchasing decisions. Building awareness is seemingly the significant reason behind cause-related marketing, a subset of Corporate Social Responsibility that is characterized by Varadarajan and Menon (1988). This type of marketing involves the cooperative efforts of a for-profit business and non-profit organization for mutual benefits. Ross, Stutts, and Patterson (1991) found that 53 percent of consumers would review a cause-related notice for a product, and Webb and Mohr (1998) found that 79 percent of buyers could portray a particular cause-related promoting effort after the idea was disclosed to them. Distinctive 
investigations show that information on Corporate Social Responsibility can significantly affect behavioral intentions in addition to the assessments of product and organizations.

Most consumers say that they acknowledge and appreciate companies that make charitable donations. Buyers additionally report that they anticipate that organizations will protect the environment and behave ethically, while periodically constructing their purchasing choices in light of these components.

The Organization for Economic Co-operation and Development (OECD) surveyed the quality of CSR communication between textile and clothing manufacturers, their consumers, and the instruments that textile and clothing manufacturers use to inform buyers about their manufacturing conditions (Fliees et al. 2007) It was found that textile and clothing manufacturers employ almost all available CSR tools, and they are more successful in doing this than the other sectors of industry such as fresh fish, cut flowers, and cosmetics. The influence of labelling on most consumers continues to be relatively weak, despite the fact that labelling is a generally acceptable source of information that can present a company as a socially responsible. With these perspectives, it is reasonable to suggest that a more detailed analysis of CSR labelling that applies to textile and clothing products appears to be very useful, as well as an evaluation of the role of labelling in product differentiation seems to be important.

\section{Fashion Trends}

Fashion products are often replaced by new ones, which make the fashion industry particularly problematic from an ecological perspective. Fashion consumption is often related to our emotional needs; it expresses our inner individual personality through symbols, brands and status items. Fashion consumers and businesses, however, have understood that this consumption pattern is 
problematic and have started making fashion ethics a point of focus; sustainability and ethical production have started to matter in the fashion industry (Emberley 1998; Moisander and Personen 2002). Organizations have understood that the fast fashion business model raises ethical issues and concerns (Aspers and Skov 2006).

Fashion and trends have driven consumers' choices in the clothing business. In 2004, eight out of ten consumers in the US said that environmental issues are important. They considered themselves consumers who want to protect the environment. However, in actuality, they do not give priority to environmental aspects when it comes to apparel shopping When they buy clothes, especially fashion items, price and style are considered important factors and often trump ethics and sustainability. Consumers' seek newness, prioritizing fashion and style which actively works against sustainable development (Fletcher 2008).

Fashion cycles are short, and the race for cost efficiency is tight. The value of goods and cost of clothing have consistently gone down. Consumers want to feel good about their consuming behavior. While making a fashion decision, consumers appreciate high quality, made-to-last properties, as well as ethical and sustainable production practice (Fletcher 2008). 


\section{Chapter Two}

\section{Literature Review}

Although several scholarly reviews have surveyed the impact of eco-labels on in-store buyer behavior (e.g., Bradu et al. 2013; Carrero and Valor 2012; Hoek et al. 2013; Sammer and Wüstenhagen 2006; Thøgersen et al. 2010; Vanclay et al. 2011), such surveys are limited in scope as they focus largely on willful labeling plans, whereby particular brands or retailers execute ecolabels for a predetermined number of fashion products to highlight their low environmental effect. Consequently, the tested labels provide only positive environmental information about these items, while few reviews consider the idea of negative labels (Grankvist et al. 2004).

A 2001 investigation of eco-labelling among 37 items in a U.S. grocery store, by Vanclay, Shortis, Aulsebrook, Gillespie and Howell offers a promising initial step towards a more comprehensive understanding of eco-labels' effect on buyer behavior. Their 8-week study revealed different effects on consumers based on household product labels, and also identified both a decline in negative labels offered in the market as well as consumers' increased inclination towards positively labeled item. Their research model also considered cost variables, with results indicating that the demand for eco products increased remarkably when the product was also priced amongst the least expensive choices, while items with high carbon footprints were rejected when they were the most expensive. While the study by Vanclay et al. (2001) suggests that generalized labelling frameworks affect changes in demand, it nonetheless leaves many unanswered questions regarding effective systems for labelling.

TemaNord's (2001a) evaluation of the Swan brand eco-label found that its general objective was to make a "contribution to reduce environment impact from consumption" (p. 18). The Swan eco-label's twofold mission was stated as follows: "to guide consumers and purchasers in 
their wish to practice environmentally conscious purchasing and to stimulate the development of products and services that are associated with a lesser environmental burden" (p. 18).

Eco-labelling, as an information tool connecting producers and shoppers, is becoming a topic of interest amongst academics. Mattoo and Singh's (1994) theoretical study, for instance, identified cost-related factors related to eco-labelling, as well as the latter's effects on the business sector, social welfare, and the environment. In contrast, researchers such as Nimon and Beghin (1999) and Blend and van Ravenswaay (1999) carried out observational research that explored buyers' preference for eco-labelling of environmental friendly products. These reviews analyzed the impact of customers' requests for eco-labelling by investigating the possibility of replacing government mediation with a market-based approach in managing ecological quality issues. The study (Blend and van Ravenswaay 1999) provided further empirical knowledge into consumer preferences about an aspect of the effort to preserve environmental quality and the adoption of environmentally favourable farming techniques for organic products.

Through eco-labelling, consumers can comprehend the environmental effect of their product choices, while producers can inform the market about their green practices. Moreover, eco-labelling helps producers foreground their ecological commitment as well as the way in which they implement such practices in their operations; as a result, such producers' market share will increase (Morris 1997). Ecological or eco-labelling turns out to be crucial for educating consumers about the benefits of environmental products (or conversely, to make them aware of any environmentally harmful products) in order change their shopping behaviors and attitudes toward more eco-friendly products (Anderson 1990; Gallastegui 2002). 
The increasing awareness about environmentally friendly items, even those bearing an ecolabel, offers no guarantee the items' ecologically favourable properties will change buyers' perceptions or shopping behaviors towards environmentally beneficial products, as consumers' socalled green behavior may be affected by the time and effort required to make such purchasing decisions regarding environmental friendly products. Young, Hwang, McDonald, and Oates (2010) identify seven critical attributes that environmental certification schemes must address: scope, accuracy, independence, precision, transparency, standardization, and cost-effectiveness.

Consumers cannot hold the state or the market accountable for the adverse condition of the economy. One may expect that producers or business people direct the economy; however, as Gulbrandsen (2006) states in the context of eco-labelling in the fishery sector, "They will undoubtedly obey unequivocally the captain's requests. The captain is the purchaser" (pp. 479480). This might be an exaggerated statement as now fashion organizations have the ability to influence customers' choice through various promotional advertisements and activities. However, the buyers' purchasing potential should not be underestimated.

A product's eco-label first attracts buyers' attention, creating a demand for that product and thus satisfying their needs through their purchase behavior. Producers often request that customers provide feedback about the product; as a result, the producers are inclined to improve the quality of the product. This is a constant improvement process that ultimately will result in sustainable consumption and production (Thedill 2009, p. 32).

Joergens's (2006) study found that buyers' choices are limited choices when buying sustainable fashion apparel, as these are less affordable. In addition, Joergens found that many consumers considered the appearance and style of sustainable fashion unappealing. Consumers also remarked that product attributes such as price, quality, and appearance are more influential 
than ethics when purchasing fashion apparel. Therefore, clothing manufacturers should not focus solely on environmental benefits to attract customers but should also provide aesthetic appeal to satisfy consumers' desires.

Conversely, Jägel, Keeling, Reppel, and Gruber's (2012) empirical study examined motivation-driven factors corresponding to sustainable fashion and consumers' consideration of "sustainability" in their buying decisions. Jägel et al. reported that such buyers had performed at least one of the following actions: reusing dress, boycotting an organization, and purchasing eco or reasonable exchange apparel. Such actions denote buyers' sensibility about ethical values such as social awareness and safeguarding the environment by purchasing eco-label products. The buyers also compromised on the quality of product and style in order to promote ethical consumption. The above statement contradicts the common perception of fashion consumption, which claims that people purchase fashion products to satisfy their needs, to be accepted in society, and to become more confident through their choices of fashion apparel.

Few studies focus on young consumers' behavioral patterns and how they perceive and respond to the green idea and sustainable practices in terms of eco-labels (Gallastegui 2002). Therefore, more research is needed to shed some light on buyer behavior related to green consumption, and to examine the effects of eco-labels on both the demand and supply side (Gallastegui 2002). This is mainly because consumers' perceptions toward eco-labels are only beginning to be understood, particularly in nations where the promotion of green activities is relatively new. Specifically, the literature lacks studies about the link between customer behavior and eco-labels in developing countries.

The role of eco-labels can be understood both from consumers' and from producers' perspectives. From the consumers' point of view, the primary goal of eco-labels is to raise 
awareness about the positive ecological impact of a product, and to provide information about its environmental characteristics (UNEP, 1997, as cited in Youssef et al. 2008, p. 134). For manufacturers, eco-labeling works as a promotional tool and as something that distinguishes a product from their competitors. Furthermore, it helps to promote an item's positive image in the market. By labelling the products and services as "eco-efficient," companies can use eco-labelling as a method to communicate and advertise a product or service's environmental benefits (Proto, Malandrino and Supino 2007, p. 670).

Ecological labelling is the transmission of sign, code, and image. It will be "decoded" by buyers and reflected through their buying decisions. Eco-labels provide significant information to the buyers regarding product characteristics and quality, and therefore directly impacts buyers' shopping choices. All things considered, it acts as a tool that communicates and essentially guarantees a product's benefits to shoppers (D’Souza et al. 2006a, p.148).

Purchasers often spend time considering the ecological information on product labels. D’Souza, Taghian and Lamb (2006b, pp. 164-165) stated that once buyers acquire information about the environmental consequences (thus increasing their knowledge), their buying behavior towards green items will positively affected. The kind of message printed on the label may likewise impact buyers' perception about the product's health and environmental risks. It is therefore crucial for producers to advertise green product information through printed labels as they have a direct influence on purchasers and can change shoppers' attitudes towards Eco-products.

TemaNord (2001b) conducted a survey of 1,323 consumers to understand purchasers' use of label and product information. The study concluded that $29 \%$ of purchasers regularly have problems understanding information about the labels, and $61 \%$ understood the information by way of text rather than through images or logos that they could not easily comprehend. Forty-four 
percent of the purchasers also considered that they were not clear about the ecological, ethical, and animal welfare factors that are addressed through labeling (Nordic Council of Ministers, 2001, p. 91).

Leire and Thidell (2005, p.1068) investigated buyers' understanding, observations, and use of product-related ecological information and concluded that the current environmental information provided on eco-products is insufficient. Their study has also shown that consumers do not understand the importance of some information on product labels. Leire and Thidell also found that environmental claims can be misleading, as they rely on selective information that uses different terminology (e.g., "environmentally friendly," "degradable," "ozone friendly") that has not been proven to influence purchasers.

Raziuddin Taufique, Siwar, Talib, Hasan Sarah, and Chamhuri (2014) conducted exploratory research that synthesized all the possible factors to measure consumer perceptions of eco-labeling of products. Towards that end, they reviewed 51 previous studies from 1981-2013. The findings showed an increasing concern for social and environmental factors that influenced consumer purchasing decisions. Raziuddin Taufique, Siwar, Talib, Hasan Sarah, and Chamhuri (2014) came up with a total of 10 parameters that included consumer awareness, consumer knowledge, consumer involvement, consumer trust, design and visibility, credibility of the source, type and level of information, clarity of meaning, persuasiveness, and private benefits. The effect of these factors on consumer perception of eco-labels was investigated using structural equation modeling (SEM) subject to the validity of each of the constructs confirmed by factor analysis.

Bradu, Orquin and Thøgersen (2013) research discovered that traceable labels significantly affect buyers' intention to purchase a chocolate bar; however, the effect is moderated by moral and emotional assessments of the product. Bradu et al. (2013) concluded that the tested labels 
exclusively provide positive environmental information about the products. All these current discoveries underscore eco-labels' ability to influence consumers' decisions in stores, by helping them to make quick judgments.

Göçer and Oflaç (2002) explored different factors influencing young consumers towards eco-labeled products, including: knowledge, concern, attitudes, adoption, confidence, mechanism, personal factors, intention, behavior, willingness to pay, consumer effectiveness, personal norms, and product-related factors. The study employed an exploratory factor analysis to distinguish the key measurements, and then structural equation modeling to test the environmental concerns. It became clear that environmental concerns and knowledge were important factors in purchasing decisions corresponding to eco-labeled products in emerging markets. The study also found that young consumers, despite their concerns about potential environmental degradation, were neither aware of eco-labels on product packages nor understood their meaning.

Vlosky, Ozanne and Fontenot (1999) analyzed the relationship between intrinsic ecological motivation and the willingness to-pay a premium price for environmentally certified items. The study suggests that there is a positive relationship between the willingness to-pay and the independent factors in the model including environmental consciousness, certification involvement, and importance of certification. The study evaluated the latter three categories using a five-point Likert-type scale ranging from strongly agree to strongly disagree. Moreover, buyers' awareness and conviction to safeguard the environment may also impact purchasing decisions. The study distinguished a cluster of U.S. customers who had a proclivity to buy certified items and who were considered to be a logical target market. This consumer profile information might be helpful for product positioning decisions in the market with respect to environmentally certified products. 
Szeniawska (2007) identified problems caused by difficulty to title labels when production chains are long, particularly in the textile and clothing industry. The fair-trade label is usually given to unprocessed goods (or low-processed ones), but even simple products such as tea or coffee give rise to many controversies about auditing and monitoring methods. Transparent control over the work of thousands of farmers, agents, and cooperatives scattered around the globe is not easy, particularly in the case of coffee which is mostly sold unprocessed. Therefore, attempting to certify the entire garment-making process, from cotton growing, fibre processing, dyeing and weaving, to cutting and sewing the fabric is much more difficult. So is the production of accessories, such as buttons, clasps, and sequins.

Małgorzata's (2011) survey of different CSR correspondence activities demonstrates that certification and labeling are the most effective instruments that can induce positive changes in customer behavior. Małgorzata's experimental research findings show that buyers respond to information attached to products and labels, but that the role certification and labeling plays in product differentiation is not sufficient. Because labeling is a basic strategy used to transmit complex messages, the inherent benefits of signs and labels need to be more fully addressed.

A limited number of studies examine buyers' awareness or information about social responsibility of organizations termed as Corporate Social Responsibility (CSR), which is a complex idea. According to Scherreik (2000), consumers have less knowledge about CSR since it is difficult for them to access and save such information about multiple organizations. Many buyers want additional information about companies' CSR activities (Scherreik, 2000).

Most of the CSR labels that are used today were created in the 1990s. As compared to the ecological labels, CSR labels are relatively new and few in number. Although some CSR labels cannot be awarded without the organization first meeting certain environmental standards, they 
primarily show the organization's sensitivity for workers' rights, occupational safety, and health rules. They also depict the organization's involvement in the well-being of local communities and in fair trade. Many CSR labelling systems have been designed to provide consumers living in developed countries with the information about producers operating in developing countries. Most of the systems correspond to exporting markets and niche products (Dickson, 2001).

While the media campaigns that promote eco-labelling apparently raise awareness amongst consumers who gradually remodel their behavior, the business community has not made much progress. One reason is the higher certification and licensing costs. Developing countries also often complain about their struggle with increasing costs that significantly impede trade (Horne, 2009).

Despite all of the limitations of the present labelling systems, they still seem to be one of the most convenient and consumer friendly channels of communication that manufacturers can use in this area. Małgorzata's (2001) research has shown that the labels can be most effective, as $70 \%$ of Polish consumers noticed a CSR message from textile and clothing manufacturers that was printed on a label or tag attached to a textile product to affirm its eco-friendly or ethical characteristics. Two factors determine the success of labelling systems: one is the awareness of consumers and their ability to understand their message, and the other one is the business community's willingness to accept the systems (Małgorzata, 2001).

Consumers are increasingly concerned about the social consequences of their purchases, especially in relation to the human rights violations in sweatshops. In addition, sweatshop labour is consumers' most important ethical concern when making apparel purchase decisions (Tomolillo and Shaw 2004). Clothing made with eco-friendly materials such as recycled materials and organic fibers, or made under fair-trade conditions, falls under the category of ethical fashion. Such fashion has become a means by which fashion companies fulfill their social and environmental 
responsibilities and match the increasing consumer demand for sustainability (Hawken 1993). In this era of globalization, when people around the world are fighting for equality and sustainability in many aspects of their lives, ethical fashion is regarded as surpassing its fundamental function of meeting basic human physiological needs by fulfilling consumers' psychological needs (Paulins and Hillery 2009).

Chan et al. (2008) evaluated Chinese consumers' assessments of recycled shopping bags and found that they are more likely to rely on ethical judgments if they perceive the recycled shopping bags to be important. In a field experiment on firewood purchases in Guatemala, (Kempen et al. 2009) found that even socioeconomically disadvantaged people express ethical and environmental concerns.

In a study by Shen et al. (2008), consumers expressed their willingness to support ethical fashion businesses, but they lacked knowledge about them. Consumer knowledge is thus essential for raising awareness about ethical fashion. In addition, Bin Shen et al. found that even though there is a low level of awareness of ethical fashion brands and fewer purchases, consumers are willing to pay a premium price for ethical fashion products. Retailers need to take the initiative to ensure the successful launch of ethical fashion products, and their advertisements should include both social and environmental messages about ethical fashion. Apparel manufacturing techniques have a significant impact on both environmental and human well-being. To tackle the social and environmental challenges that the industry faces, consumers, designers, retailers, and other industry insiders all need to participate and show their responsibility.

As indicated by the Ethical Fashion Forum (2014), almost $75 \%$ of the world's apparel export is manufactured in developing countries under unhealthy and hazardous conditions. These problems with adverse working conditions, which Wilson (2003) among many other critics 
collectively refer to as sweatshop labour, should be addressed. This will provide better working conditions to supply chain and manufacturing workers in the apparel industry.

Since the early 2000s, fashion has become faster and cheaper. Global communications and marketing, together with increased competition and the growth of offshore manufacturing, have increased demand and higher consumer expectations. This creates unsustainability for fashion in both the short and long term. The current focus on fashion and sustainability is due to the convergence of many environmental and commercial factors, together with changing cultural and social norms. Cheap fashion means disposable fashion, and encourages more consumption, creating a vicious circle (Black 2008, p. 11). The clothing and textile sector is a significant economic player, employing over a billion people worldwide. Relative to income, clothes are now far cheaper than they were a few decades ago (Julian Allwood 2007).

H\&M included natural cotton for its children's garments and completely sold out limited edition organic cotton T-shirts designed by Stella McCartney in 2005 (Jana 2006). After Wal-Mart announced its plan to double its organic products in March 2006, it decided to manufacture the George Baby line of newborn children dresses made with $100 \%$ natural cotton. Both Nike and Patagonia also made a public commitment to use renewable materials for their new productions. Nike had shifted towards incorporating at least $5 \%$ certified organically developed cotton into all cotton clothes sold internationally by 2010 (Jana 2006). Levi Strauss and Co. has a line of organic cotton pants, which highlight the fabric's composition including colours and a label made of reused paper printed with environmentally friendly soy ink. This superior label, Capital E jeans, bears a hefty price tag of $\$ 250$, since organic cotton is relatively less available.

With many companies introducing an array of eco-friendly garments with various fabrics, there comes a question of supply and demand. These eco-friendly fabrics are not cheap. How much 
are fashion clothing companies willing to spend on producing their products if a consumer is hesitant to purchase the more expensive alternative? Linda Lundstrom, one of Canada's top fashion designers has been pushing her strong environmental initiatives for the past two decades. That's the moral dilemma, Lundstrom said: "I can get fabric that's less money and looks the same. The earth-friendly dye process isn't without glitches. You can't get the same colors as with synthetic dyes. It is expensive to produce more environmentally friendly fabrics" (as cited in Seiberling 2007, p. 1). In her letter to suppliers, Lundstrom told them: "We believe that the heart and soul of a company is what they do for no commercial reason, with no guarantee of financial success, but simply because it's the right thing to do" (as cited in Seiberling 2007, p. 1).

The worldwide demand for textile fibre is increasing with two fibres dominating the expanding market: cotton and polyester. Polyester has now overtaken cotton as the single most popular textile material, and over the last 15 years its demand has doubled. Surveys repeatedly show that there has been tremendous confusion over the sustainability impacts of producing textile materials (Fletcher 2008). Given that fashion is a cultural, economic, or social phenomenon, the concept of eco-fashion may seem a contradiction. Whether a garment is made from organic cotton, recycled fabrics, or made of less waste, perceptions are changing of sustainable and ethically sourced material.

Eco-fashion is becoming stylish. This eco-fashion movement began in the mid-1970s, stemming from the hippie revolution. Back then, it was considered more anti-fashion and characterized by alternative lifestyles from homemade, ethnic, and hand-crafted fabrics as the norm. The second wave became more commercial in the 1990s. Esprit, an eco-aware company established in San Francisco in the 1960s, launched its eco-friendly collection in 1994. Esprit's environmental charter was ambitious and wide reaching, including plans to: 
- Eliminate or minimize the use of manmade fibers.

- Influence the fashion industry.

- Minimize load on landfills use recycled and biodegradable materials.

- Encourage sustainable agriculture and farming.

- Work with businesses that share our ethical and environmental goals.

- Maximize product life through classic design and durable construction. (Black, 2008, p. 12)

These plans serve as basic guidelines that most apparel companies with eco-friendly intentions tend to follow. In the last few years, more small, ethical, and ecologically motivated fashion companies have been established. The momentum and debate has grown exponentially. The current focus on fashion and sustainability is due to the convergence of many environmental and commercial factors, together with changing cultural and social norms (Black 2008).

Today, consumers and designers come across terms such as sustainable, organic, green, fair trade, ethical, eco, bio, and environmental. Such terminology needs to be understood so consumers can make informed choices. Fashion purchasing decisions are based on desires rather than needs. The industry needs to maintain balance so that clothes regain some of their long-term value and become less disposable. If consumers and designers are better informed, they could be inspired to understand the complexities regarding the environment and how everyone can make a contribution to environmental sustainability. It is up to consumers and new-generation thinkers alike to be the catalysts to energize and implement a range of new approaches (Black 2008). Designers' roles inherently have ethical and ecological implications-responsibilities for choices in materials and production processes and changing to embrace sustainable technology. 
Since fashion is both a verb and a noun (i.e., something that is created, expressed, and worn by people), fashion offers myriad opportunities for people to take sustainable actions (Hethorn and Ulasewicz 2008). Many have asked the question, "Why now?" It is important to recognize the following factors to identify our place within this new fashion frontier:

- The over consumption of clothing is based on an old model and is not fashionable.

- People have the power to support with their purchases the growth of sustainable practices of retailers and manufacturers.

- Sustainable fashion can enhance the physical, emotional, and psychological well-being of people.

- People are the driving force behind sustainable choices in the fashion industry. (Hethown and Ulasewicz 2008, p. 5)

According to this literature review, environmental, social, and ethical responsibility have not been examined along with the eco-labelling in a single study pertaining to the fashion industry. While a combination of two of the latter aspects are found in some of studies, gaps still exist with regards to global research related to eco-labelling in fashion. Lack of scholarship in the factors mentioned above along with lack of research conducted from a Canadian perspective has motivated me to take up this research study. Further studies that focus on consumer perspectives towards green market and eco-friendly products in the fashion industry are needed. 


\section{Research Purpose}

This study focuses on fashion consumers' behavior toward eco-labelling with respect to four factors: the current fashion system, environmental responsibility, ethical responsibility, and social responsibility. This study aims at preparing a framework for measuring the consumer response on eco-labelling with respect to the aforementioned factors, identifying the impact of eco-labelling on consumer purchase decisions and also exploring the relationship among these four areas. This research will examine consumers' perceptions, knowledge, and experience about sustainable fashion in general and eco-labelling in particular.

This study seeks to explore the effectiveness of the increasing number of eco-labels and the different methods used to identify customers' understanding and impression of such labels. In this study, a set of important and comprehensive factors will be identified to investigate consumers' perception, knowledge, and experience about sustainable fashion and eco-labels.

\section{Hypotheses}

Vlosky et al. (1999) analyzed the relationship between intrinsic ecological motivation and the willingness to-pay a premium price for environmentally certified items. Their study suggests that there is a positive relationship between the willingness to-pay and the independent factors in the model including environmental consciousness, certification involvement, and importance of certification. Moreover, buyers' awareness and conviction to safeguard the environment may also impact their buying behavior. Paromita Goswami (2008) proposed a model to help identify if consumers are willing to pay more for ecological clothing products, given that eco-label products are more expensive than products without eco-labels. The model includes three variables: involvement in environmental certification, importance of certification, and willingness to pay more for environmentally certified cloth. In consideration of the above discussion, the following 
hypothesis was proposed:

H1: There is significant relationship between importance of certification, involvement in certification and purchasing behavior.

A large number of consumers are buying environmentally friendly products and many have shown their willingness to pay higher prices for such products. Studies have shown that concern about the environment is rising and that people are participating in activities that help to protect the environment (Borin et al. 2011). Environmental concern was an important purchasing decisions for eco-labeled products in emerging markers. To tackle the social and environmental challenges that the industry faces, consumers, designers, retailers, and other industry insiders all need to participate and show their responsibility (Göçer and Oflaç 2002). Thus, a second hypothesis was developed.

$\mathrm{H} 2$ : There is significant relation between environmental responsibility and purchasing behavior.

Consumers are increasingly concerned about the social consequences of their purchases, especially in relation to the human rights violations in sweatshops (Tomolillo and Shaw 2004). According to Scherreik (2000), consumers have less knowledge about social responsibility since it is difficult for them to access and save such information about multiple organizations. There are numerous buyers who want additional information about the social responsibility records of companies. Małgorzata's (2011) survey of different CSR correspondence activities demonstrates that certification and labeling frameworks are the most effective instruments that can induce positive changes in customer behavior. Based on the above discussion, a third hypothesis was proposed. 
H3: There is significant relationship between social responsibility and purchasing behavior.

A broad collection of studies identifies customer purchasing behavior and ethical issues (e.g., Callen-Marchione and Ownbey 2008; Carey et al. 2008; Nicholls and Lee 2006). Carrigan and Attalla (2001) focus on the impact of good and poor ethical conduct on buyers' purchasing behavior. Creyer (1997) sought to identify if consumers paid attention to business ethics before purchasing a product, and claimed that because they did so, organizations should support ethical behavior to increase their sales. Thus, a fourth hypothesis was developed.

H4: There is a significant relationship between ethical responsibility and purchasing behavior.

In the last few years, a greater number of small, ethical, and ecologically motivated fashion companies have been established. Fashion purchasing decisions are based on desires rather than needs (Black 2008). In the fashion business, multinational organizations such as Nike, GAP, Marks and Spencer, Timberland, and Levi Strauss have increasingly invested resources in producing socially responsible fashion. For instance, H\&M and MUJI have even introduced an organic collection (Beard 2008; Chan and Wong 2012; De Brito et al. 2008; Fletcher 2008; Joergens 2006; Shen et al. 2012).

H5: There is significant relationship between fashion trends and purchasing behavior.

Ecological or eco-labelling turns out to be crucial for educating consumers about the benefits of environmental products as well as to make them aware of the environmental harmful substances in order change their shopping behavior and attitudes toward more eco-friendly products (Anderson 1990; Gallastegui 2002).Buyers' actions such as recycling, boycotting an organization, and purchasing eco-friendly apparel indicate their sensibility about ethical values 
such as social awareness and safeguarding the environment by supporting eco-label purchasing. It indicates also that consumers are willing to compromise on products' quality and style in order to promote ethical consumption. The above statement contradicts the debate on fashion consumption which, as noted earlier, asserts that people purchase fashion products to satisfy their needs. They also want to accept in society and they want to be more confident through their choices of fashion apparels (Jägel et al. 2012). In consideration of the above discussion, the following hypothesis was developed:

H6: There is significant relation between environmental responsibility, social responsibly, ethical responsibility, and eco-labelling. 


\section{Chapter Three}

\section{Research Methodology}

For this research of fashion consumer behavior toward eco-labelling, I stand on the objectivist position for ontological considerations and positivism for epistemological considerations. There are two main reasons that I take these positions to conduct this research. Firstly, this study does not try to explain or interpret the meaning of consumer buying behavior surrounding ecological fashion products. Instead, this research study is focused on finding the general rule in order to predict consumer behavior: whether their purchasing behavior can be predicted by their awareness of eco-labels, their environmental motivation, their eco-knowledge and their eco-availability. Secondly, the relation between these factors and purchase behavior is considered objective. It exists independently and outside of the researcher's insight.

Furthermore, the study follows a quantitative method with a deductive approach because the purpose of the research is testing theory. Firstly, I started by reviewing theories about fashion consumer behavior surrounding eco-labelling. Secondly, I derived a model of relations between four factors (environment, social responsibility, ethical responsibility, fashion trend) found on ecolabels and purchase behavior regarding ecological fashion products. A hypothesis will be developed in the next step to test the model. It is expected to come up with results of either rejecting or confirming hypothesis. Finally, the model and theory will both be revised for compatibility with research results.

\section{Research Strategy}

In general, quantitative and qualitative research methods are selected for different purposes. This research only applies quantitative research as this study purpose is to explain or predicate fashion 
consumer behavior of eco-labelling and the relationship between four factors (environment, social responsibility, ethical responsibility, fashion trends). However, it is not important to understand and describe consumers' point of view. Thus, quantitative analysis is much more appropriate for my research purpose. Plus, the advantage of quantitative research is that it can be brought into full play in the research. Based upon the statement from Johansson (1995, p.9), quantitative research has advantages entailing a measurement about large numbers of respondent answers to get comparative and statistical aggregations. This advantage is important for my research as this study contain large number of respondents.

Qualitative research is not as appropriate as quantitative research because the detailed information from a small number of people cannot benefit the research. And this study needs hard reliable data rather than rich deep data to get an objective result.

\section{Research Design}

For my study I chose a cross-sectional research design (social survey) to support my arguments and findings. Bryman and Bell (2007, p.55) define cross-sectional design as "the collection of data on more than one case (usually a lot more than one case) and at a single point in time in order to collect a body of quantitative or quantifiable data in connection with two or more variables, which are then examined to detect pattern of association." Cross-sectional studies attempt to describe the incidence of a phenomenon or compare factors in different organizations (Saunders et al. 2000, p.96).

In quantitative methods, the term cross-sectional design is often used to imply social survey research. Survey research includes all elements of cross-sectional design. Plus data in survey research is frequently collected by questionnaire or structured interview (Bryman and Bell 2007, 
p. 56). Rossi, Wright and Anderson (1983, p.1) explained in detail with a similar name: "sample survey." Sample survey comprises the collection of information on individuals, households, or large organized entities through the questioning of identified samples by systematic, standardized approaches (Rossi et al. 1983, p.1). There are three basic components cohering to distinguish a sample survey:

- Sampling non-institutionalized human populations: the purpose is to select the unbiased samples of the non-institutionalized population.

- The art of asking question: questionnaire and interview schedules need to be created in the way that provokes valid and reliable answers.

- Multivariable data analysis: data analysis process with the application of statistic enable the calculation of the relation between numerous variables in a complex relationships (Rossi et al. 1983, pp 1-2)

Discuss further about choosing cross-sectional as research design, there are key elements which is compatible with this research. Firstly, the study can examine more than one single case. Secondly, the variables are collected almost simultaneously right after the individuals complete the questionnaire (questionnaire includes 46 variables). Finally, the relationships between variables can be tested by statistical methods such as correlation and regression.

A cross-sectional design also has some limitations, which are caused by the nature of the design. One obstacle is that the researcher cannot establish the direct causal influence of variables that are examined. The accuracy of measuring variables is also very important for this research design. Questionnaire design was given special attention in order to reduce unreliability and strengthen the validity of the research. The main advantage of this design is the representation of the multiple cases. 


\section{Convenience sampling}

This research applies convenience sampling. Convenience sampling is "a sampling technique in which interviewers are asked to find respondents who happen to be conveniently accessible" (Kent 2007, p.235). Since interviewers can collect the completed questionnaire back immediately, the response rate of using convenience sampling is good. Even though such a sampling strategy has been widely used, it is not without problems. The usage of such strategy cannot ensure the sample representative of the whole population (Saunders et al. 2000, p.147; Bryman and Bell 2007, p.198).

Using the convenience sampling method, one can send a link to the online questionnaire to individuals on their mobile phone's contact list, to individuals you are connected to via social networking websites such as Facebook, LinkedIn and Google+ and, more effectively, to individuals whom you know in person. This proved to be the easiest and most convenient way of recruiting sources to supply primary data for the research.

\section{Self-complete questionnaire}

The self-complete questionnaire is sometimes called a self-administered questionnaire. This type of questionnaire requires respondents to complete the questionnaire themselves (Bryman and Bell 2007, p.240). According to Saunders et al., (1997, p.245), the self-administered questionnaires are divided as postal questionnaires, and delivery and collection questionnaires according to the methods of distribution. Bryman and Bell (2007, p.240) stated these two options as well. The first option is to mail the questionnaire directly to selected respondents. In order to collect these questionnaires back, the researcher can ask respondents to mail the complete questionnaire (Bryman and Bell 2007, p.240). The other option for researchers is to choose a class in an educational institution and distribute to all the target students within the class. In this case, 
researchers can collect their questionnaires as soon as those respondents complete their answers (Bryman and Bell 2007, p.240). In general, this option requires researchers to deliver the questionnaire "by hand to each respondent and collected later" (Saunders et al. 1997, p.245).

When it comes to reasoning for selection, the decision is made by considering both the advantages and disadvantages of a self-completion questionnaire. Finally, it is believed that selfcompletion questionnaires suit my research. The advantages and disadvantages are outlined as follows:

- Advantages: Bryman and Bell (2007, p.241) identified the benefits of self-completion questionnaires as cost savings, "quick to administer", "absence of interviewer effects", "no interviewer variability", and "convenience for respondents". Compared with using postal questionnaires, online questionnaires are cheap and quick to administer. Secondly, one can collect large quantities of data in short amount of time. The respondents might come from different countries so that they can provide diverse answers to the questions to enrich the data. Thirdly, the interviewer can eliminate bias and interviewer effects by removing him or herself from the respondent. Finally, "self-completion questionnaires do not suffer from the problem of interviewers asking questions in a different order or in different ways" (Bryman and Bell 2007, p.242).

- Disadvantages: the disadvantages mentioned by Bryman and Bell (2007, pp. 242-243) are as follows: "cannot prompt", "cannot probe", "cannot ask many questions that are not salient to respondents", "difficulty of asking other kinds of questions", "questionnaire can be read as a whole", "do not know who answers", "difficult to ask a lot of questions". Some of these disadvantages like, "cannot probe," or, "difficulty of asking other kinds of questions," are thought to have less effect on the result of my research because this research 
does not need elaboration of answers. Some other disadvantages, such as "do not know who answers," and "lower response rate," are related with this research.

\section{Recruitment Method}

Participant selection criteria was based on age (18 years or above). The participants were recruited by friends and colleagues, e-mail blasts and online via social media (Facebook).

"Social media is a term used to describe networks and communities of people who create and share content online, typically on closed systems rather than on the World Wide Web as a whole. Social media is a relatively recent phenomenon becoming widespread only in the mid-tolate 2000 's. By the early 2010's, social media's most popular websites, Facebook and Twitter, had become a ubiquitous part of American life, with tens of millions of participants" (Friedland, 2013).

Today, the two biggest and most important social medial platforms for in art world: Facebook and Instagram. These two online giants have become key players for the fashion market. Statistics revealed 52\% respondents regarded Facebook among the most important social media channels for fashion-related purposes, followed by $34 \%$ who said Instagram was also important (Davis Ben 2014).

Therefore, among all social media platforms, Facebook was the most efficient way of approaching the fashion community in my network. Its visual consumption provides product images to circulate in a faster and easier way. Consequently, images often end up as sales, even though Facebookis is not an e-commerce site. Ironically, because of its visual content, it has become a perfect space for trade. Furthermore, it is believed the use of social media to influences fashion market trends, and market art directly to buyers will continue to grow. More taste makers 
in the fashion world register with a social networking platform and more users seek them out (Davis Ben 2014).

Because of its easy access, social media also helps facilitate validation for posted images and increases buyer confidence. The last Hiscox Report survey expressed that $24 \%$ of respondents alleged that social media activity had an influence on their buying decisions. That is why I chose Facebook to reach an audience of fashion consumers.

I chose to conduct an online survey instead of a paper survey because web surveys provide people different screen resolutions, font sizes, and can be accessed digitally on different electronic devices. They can even be filled out and submitted from a mobile phone. All you need is a reliable internet connection. Therefore, web surveys allow for engagement with various types of people.

Response rates are ten times higher with web surveys and data begins to accumulate within minutes (RF Schoeni, 2013). On the other hand, paper-based surveys may take weeks or even months to distribute, collect, and review for results. Paper surveys require an additional cost for printing and if you hire a professional, may cost even more. The Internet provides a variety of options to explore when it comes to survey making. With quality websites such as SurveyMonkey, it doesn't cost much to prepare your own survey within minutes. It has pre-built themes, readymade templates, unlimited question options to provide structure to your survey and can be disseminated through social media. Users are also provided with text answer areas, with automatic spell checks for the least chance of grammatical mistakes to provide intelligible data.

It is not feasible to disseminate a paper survey among an international audience, or even within country. Free online surveys provide users an option to market their surveys anywhere 
online through emails, social networks, company websites or blogs, and other blogs related to your industry. You can reach a global audience within a few seconds (Kelvin Stiles 2014).

\section{Ethical Consideration}

"Ethics are moral principles or standards that guide the ways in which individuals treat their fellow human beings in situations where they can cause actual or potential harm, whether economic, physical or mental" (Kent 2007, p.38). Specific to marketing research, it is even more essential to protect respondents from harm because, "good ethical standards are good business" (Kent, 2007, p.38). Regarding my research, I followed ethical standards for keeping participant identification and personal data confidential. The results were not shared with any third party. All respondents were kept anonymous. This research survey was also free of deception. A pilot test run was conducted ahead of release, so the approximate time of answering the questionnaire could be estimated. I informed my potential respondents about the approximate time for completing the questionnaire before they answered the questions.

Consent forms were added in the questionnaire so participants were made aware of the nature of the study and their rights as research participant. In order to control the sample and avoid the issue of parental consent, this research focused on participants 18 years old or above. Participants were also made aware in the consent form that collected data would be kept in a password-protected computer database. All information would be kept confidential. 


\section{Instrument Design}

The instrument used to generate findings was an anonymous survey. The instrument was structured using closed formed questions, in the form of a Likert scale, pertaining to participant's consumer behavior in relation to eco-friendly fashion. The survey included a cover letter, instructions, and a survey. The respondents were instructed to read the cover letter, instructions, and then complete the survey. They had the option of not completing the survey or participating in the study. The questionnaire consisted of five sections: Eco-labelling, consumer behavior, fashion trends, social and ethical behavior and demographic. The participants were asked to read each question and answer based on the Likert scale model. The Likert scale is five point scale which allow the individuals to express how much they agree or disagree with a particular statement.

The respondents ranged in age from 18 or older. Demographic questions also asked respondents' gender age, education level, annual household income and residence. Data was collected through an online questionnaire with no specific geographic location. The survey consisted of questions about consumer knowledge or notions of eco-labelling with respect to the fashion system's environmental responsibility, ethical responsibility and social responsibility. Basically, it measured the impact of eco-labeling on consumers' actual purchasing choices. I attempted to research eco-fashion as a brand/product element and questioned its practicality and importance within the current fashion system.

All data was coded and entered into SPSS statistical software for analysis. The following steps were used to analyze the data, interpret and present results, and draw meaningful conclusions from the findings. 


\section{Sample}

A total of 332 useable respondents surveys were analyzed in this study. The survey contained a total of 47 questions. All questions were compulsory to answer but a small number of few respondents skipped a few questions. For this reason, some of the tables may show respondents number less than 332. Questions that were determined as irrelevant to the findings of this study have been omitted.

\section{Questionnaire Design}

The questionnaire (Appendix 1) is mainly constructed with five parts. The first part of questionnaire contains 30 questions (Question 2 to 31). These questions are used for testing environmental consciousness, importance of certification, involvement in certification, willingness to pay, commitment towards eco-labels, environmental concern, eco-label product price, eco-label product quality, brand image and purchasing behavior of consumers toward ecolabels. Respondents are required to rate from 1(strongly agree) to 5(strongly disagree). The second part (question 32) consists of 13 sub questions regarding ethical purchasing behavior of consumers about fashion related products. Respondents are required to rate from 1(very important) to 5(very unimportant). The third part (question 33 to 38) is about consumer behavior towards current fashion system. Respondents are required to rate from 1(strongly agree) to 5(strongly disagree). The fourth part (question 39) consists of eight sub questions about the importance of social factors in consumers purchasing behavior. Respondents are required to rate from 1(very important) to 5(very unimportant). The fifth part of the questionnaire includes seven questions (from question 40 to 47). These questions refer to demographic characters of respondents (gender, yearly income, age, education, employment status, country and current relationship status). 


\section{Analytical Methods}

A descriptive and experimental quantitative research design was used to fully explore the research topic. Descriptive design is simply the collection and report of raw data related directly to the subject population of the study (Keith Muller 2002). Experimental design analysis of variances (ANOVA) was used to determine whether there were any statistically significant differences between the means of three or more independent (unrelated) groups. The one-way ANOVA compares the means between the groups you are interested in and determines whether any of those means are statistically significantly different from each other.

Analysis of variances was helpful for testing three or more variables. It is similar to multiple two-sample t-test. However, it results in fewer types I error and is appropriate for a range of issues. ANOVA groups differences by comparing the means of each group and includes spreading out the variance into diverse sources. It is employed with subjects, test groups, between groups and within groups (Keith Muller 2002).

\section{Correlation}

In experimental design, "a correlation exists if, when one variable increases, another variable either increases or decreases in a somewhat predictable fashion" (Leedy and Ormrod 2010, p. 183). A correlation coefficient is the "resulting statistic" from a process by which researchers discover "whether two or more variables are in some way associated with one another" (Leedy and Ormrod 2010, p. 273). This coefficient is a number between -1 and +1 . A positive correlation (identified by a positive number) indicates a parallel relationship between the two variables. When one variable increases, so does the other variable (Leedy and Ormrod 2010). A negative correlation (identified by a negative number) indicates an inverse relationship between the variables. As one 
variable increases, the other variable decreases (Leedy and Ormrod 2010). The strength of the correlation is simply measured by the size of the coefficient. "A correlation of +1 or -1 indicates a perfect correlation" (Leedy and Ormrod 2010, p. 273). Therefore, the closer the coefficient is to either numeric value, the stronger the correlation is between the variables.

\section{Hypothesis Testing}

Hypothesis testing or significance testing is a method for testing a claim or hypothesis about a parameter in a population, using information measured in a sample. It is a procedure, based on sample evidence and probability theory, used to determine whether the hypothesis is a reasonable statement and should not be rejected, or is unreasonable and should be rejected (Trosset 2006).

\section{FIVE STEPS IN THE HYPOTHESIS TESTING PROCEDURE}

1. State the null hypothesis and the alternate hypothesis.

Null Hypothesis is a statement about the value of a population parameter.

Alternate Hypothesis is statement that is accepted if evidence proves the null hypothesis to be false.

2. Select the appropriate test statistic and level of significance.

F-test is used when comparing statistical models that have been fitted to a data set in order to identify the model that best fits the population from which the data was sampled.

A traditional guideline for choosing the level of significance is as follows:

(a) The 0.10 level for political polling, (b) the 0.05 level for consumer research projects, and (c) the 0.01 level for quality assurance work. 
3. State the decision rules

The probability of obtaining a sample mean, given that the value stated in the null hypothesis is true, is stated by the $\mathrm{P}$ value. A $\mathrm{P}$ value is the probability of obtaining a sample outcome, given that the value stated in the null hypothesis is true. The $\mathrm{P}$ value for obtaining a sample outcome is compared to the level of significance.

If $\mathrm{P}$ value is less then level of Significance, reject Null hypothesis

4. Compute the appropriate test statistic

F-statistics use this formula:

F Statistic $=$ variance of the group means $/$ mean of the within group variances.

Compare the computed test statistic with critical value. If the computed value is within the rejection region(s), we reject the null hypothesis; otherwise, we do not reject the null hypothesis.

\section{Interpret the decision}

The value of the test statistic is used to make a decision about the null hypothesis. Reject the null hypothesis if the sample mean is associated with a low probability of occurrence when the null hypothesis is true. Retain the null hypothesis if the sample mean is associated with a high probability of occurrence when the null hypothesis is true (Trosset 2006). 


\section{Chapter Four}

Findings and Analysis

\section{Findings and Analysis}

This chapter presents the findings gathered throughout the course of my research. The collection of data was carried out principally through an online questionnaire which addressed consumers' knowledge and notions of environmental, ethical, and social responsibility, eco-labelling, and the fashion system in general. All participants were 18 years of age or older. A total of 332 useable respondents' surveys were analyzed in this study.

\section{Variables and Consistency}

In total, sixteen variables (coded below) were targeted through [number] questions which participants answered according to a five-level Likert scale, i.e. with possible answers ranging from 1 (Very High/Strongly Agree) to 5(Very Low/ Strongly Disagree). Cronbach's alpha was then applied to measure the internal consistency of respondents' answers.

\section{Coding of Variables}

$\mathrm{X} 1=$ Environmental Consciousness, $(\mathrm{Q} 2+\mathrm{Q} 3+\mathrm{Q} 4+\mathrm{Q} 5+\mathrm{Q} 6) / 5$

$\mathrm{X} 2=$ Importance of Certification, $(\mathrm{Q} 8+\mathrm{Q} 7) / 2$

$\mathrm{X} 3=$ Involvement in Certification, $(\mathrm{Q} 10+\mathrm{Q} 9) / 2$

$\mathrm{X} 4=$ Willingness to Pay, $(\mathrm{Q} 13+\mathrm{Q} 11+\mathrm{Q} 12) / 3$

$\mathrm{X} 5$ = Commitment toward Eco-Labelling, $(\mathrm{Q} 18+\mathrm{Q} 16+\mathrm{Q} 17) / 3$

X6 = Eco-Label Fashion Product Price, $(\mathrm{Q} 19+\mathrm{Q} 20+\mathrm{Q} 21) / 3$

X7 = Eco-Label Fashion Product Quality, (Q27+Q26)/2

$\mathrm{X} 8=$ Brand Image, $(\mathrm{Q} 22+\mathrm{Q} 23+\mathrm{Q} 24+\mathrm{Q} 25) / 4$

$\mathrm{X} 9=$ Purchase Behavior, (Q30)

$\mathrm{X} 10=$ Environmental Responsibility, $(\mathrm{X} 1+\mathrm{X} 5+\mathrm{X} 6) / 3$ 
$\mathrm{X} 11=$ Ethical Responsibility, (Q32) (8 sub-questions)

$\mathrm{X} 12$ = Social Responsibility, (Q39) (13 sub-questions)

$\mathrm{X} 13=$ Fashion Trend, $(\mathrm{Q} 33+\mathrm{Q} 34+\mathrm{Q} 35+\mathrm{Q} 36+\mathrm{Q} 37+\mathrm{Q} 38) / 6$

Using SPSS, the alpha coefficient of each variable was calculated, as displayed in Table 1. The usual benchmark of 0.7 or higher as a score of good consistency was employed, and according to this, respondents' answers proved to be internally consistent with respect to all sixteen variables.

\begin{tabular}{lc}
\hline Variables & Cronbach's Alpha \\
\hline Environmental Consciousness & .834 \\
Importance of Certification & .825 \\
Involvement in Certification & .803 \\
Willingness to Pay & .806 \\
Commitment toward Eco-Labels & .810 \\
Eco-label Fashion Product Pricing & .808 \\
Eco-label Fashion Product Quality & .822 \\
Brand Image & .839 \\
Fashion Trend & .848 \\
Ethic Responsibility & .827 \\
Social Responsibility & .824 \\
Environment Responsibility & .809 \\
Eco-labelling & .799 \\
\hline
\end{tabular}

Table 1. Cronbach's Alpha for Each Variable 


\section{Demographic Profile}

Respondents were asked to select their age bracket, gender, level of education, employment status, annual income bracket, relationship status, and country of residence.

The largest age group (Table 2) amongst respondents was that of 25 to 34, at 38.3\%, followed by 18 to 24 at $20.2 \%, 35$ to 44 at $16.3 \%$, and 45 to 54 at $14.5 \%$. The age bracket of 55 or above had the lowest representation, at $10.1 \%$. Gender (Table 3) was fairly equally represented in the sample, with respondents who identified as male at $50.8 \%$ and female at $48.6 \%$.

Educational backgrounds (Table 4) showed that the highest level of education completed by most participants, at $45.5 \%$, was post-secondary, followed by a Master's degree at $34.9 \%$, secondary school at 14.2\%, and Doctorate degrees at 3.9\%. Employment statuses (Table 5) accorded with educational backgrounds, with $44.9 \%$ of respondents reporting full-time employment, $20.5 \%$ student status, $16.9 \%$ self-employment, and $1.8 \%$ unemployment. Other employment statuses with an even lower representation (i.e. than 1.8) were combined together under "Other" and together comprised 15.6\% of respondents. Annual incomes were more evenly distributed (Table 6), with respondents most frequently selecting the highest income bracket, "More than \$95,000" (22.6\%), and the lowest, "Less than \$44,000" (19.3\%). In between, 16\% responded with " $\$ 60,000$ to $\$ 75,000 ”, 15.4 \%$ with “ $\$ 86,000$ to $\$ 95,000 ”, 12.7 \%$ with " $\$ 76,000$ to $\$ 85,000 "$, and $12 \%$ with " $\$ 45,000$ to $\$ 59,000 "$. A small percentage of respondents preferred not to disclose their income $(2.1 \%)$.

As to relationship status (Table 7), the majority of respondents were either married $(50.6 \%)$ or single $(35.8 \%)$. Other relationship statuses were not felt to be statistically significant and so were grouped under "Other" at $13.2 \%$. Finally, geographically nearly three quarters of the 
sample resided in either Canada $(38.9 \%)$ or Pakistan $(31.9 \%)$. China came in third at $9.6 \%$ while remaining countries, individually insignificant, collectively made up the final $20.1 \%$ of respondents' country of residence (the US at 6\%; Australia at 2.7\%; Saudi Arabia at 3.3\%; Singapore at 1.2\%; the UK at 1.5\%; and Bahrain, Angola, Italy, Qatar, Poland, Panama each at $0.9 \%)$

\begin{tabular}{lcc}
\hline & Frequency & Percent \\
\hline 18 to 24 & 67 & 20.2 \\
25 to 34 & 127 & 38.3 \\
35 to 44 & 54 & 16.3 \\
45 to 54 & 48 & 14.5 \\
55 or above & 33 & 10.1 \\
Undisclosed & 3 & 0.9 \\
\hline
\end{tabular}

Table 2. Age

\begin{tabular}{lcc}
\hline & Frequency $(\mathrm{N}=332)$ & Percent \\
\hline Male & 167 & 50.3 \\
Female & 162 & 48.8 \\
Undisclosed & 3 & 0.9 \\
\hline
\end{tabular}

Table 3. Gender

\begin{tabular}{lcc}
\hline & Frequency & Percent \\
\hline High School Diploma & 47 & 14.2 \\
Post-Secondary Education & 151 & 45.5 \\
Master's & 116 & 34.9 \\
Doctorate & 13 & 3.9 \\
Undisclosed & 5 & 1.5 \\
\hline
\end{tabular}

Table 4. Level of Education

\begin{tabular}{lcc}
\hline \multicolumn{1}{c}{} & Frequency & Percent \\
\hline Employed Full-Time & 149 & 44.9 \\
Student & 68 & 20.5 \\
Self-Employed & 56 & 16.9 \\
Unemployed & 6 & 1.8 \\
\hline Other & 47 & 15.6 \\
\hline Undisclosed & 6 & 1.8 \\
\hline
\end{tabular}

Table 5. Employment Status 


\begin{tabular}{lcc}
\hline & Frequency & Percent \\
\hline$\$ 0-\$ 44,000($ USD) & 64 & 19.3 \\
$\$ 45,000-\$ 59,000($ USD) & 40 & 12.0 \\
$\$ 60,000-\$ 65,000($ USD) & 28 & 8.4 \\
$\$ 66,000-\$ 75,000($ USD) & 25 & 7.5 \\
$\$ 76,000-\$ 85,000($ USD) & 42 & 12.7 \\
$\$ 86,000-\$ 95,000($ USD) & 51 & 15.4 \\
More than $\$ 95,000($ USD) & 75 & 22.6 \\
Undisclosed & 7 & 2.1 \\
\hline
\end{tabular}

Table 6. Annual Income

\begin{tabular}{lcc}
\hline & Frequency & Percent \\
\hline Married & 168 & 50.6 \\
Single & 119 & 35.8 \\
Other & 38 & 13.2 \\
Undisclosed & 4 & 1.2 \\
\hline
\end{tabular}

Table 7. Relationship Status

\begin{tabular}{lcc}
\hline & Frequency & Percent \\
\hline Canada & 129 & 38.9 \\
Pakistan & 106 & 31.9 \\
China & 32 & 9.6 \\
Other & 58 & 20.1 \\
Undisclosed & 7 & 2.1 \\
\hline
\end{tabular}

Table 8. Country of Residence

\section{$\underline{\text { Awareness of Eco-Labels }}$}

When asked about common textile eco-labels (Table 9), respondents most frequently reported unawareness out of all of them. The best-known eco-label amongst participants was the Fair Trade label, recognized by $36.6 \%$, followed by the Clean Clothes Campaign at $18.4 \%$. The remainder of eco-labels and their organizations were recognized by a negligible percentage of the sample (the Global Organic Textile Standard at 4.8\%, the Oeko-Tex Standard 100 at 3.6\%, Care and Fair Siege at $1.2 \%$, and the Fair Wear Foundation at $1.5 \%$ ). 
When asked how much they spend on clothing annually, the majority said they spent $20 \%$ or less: $24.7 \%$ reported they spent "5\% to $10 \%$ " of their income, $22.6 \%$ spent "less than 5\%", $19 \%$ spent between "10\% and 15\%", and 17.5\% spent between "15\% and 20\%". By contrast, $7.8 \%$ of respondents said they spent "20\% and 25\%" of their income, 3.9\% spent between "25\% and 30\%", and only $4.2 \%$ spent more than that.

\begin{tabular}{lcc}
\hline & Frequency & Percent \\
\hline Fair trade & 105 & 31.6 \\
Care \& Fair-Siege & 4 & 1.2 \\
Global Organic Textile Standard & 16 & 4.8 \\
Fair Wear Foundation & 5 & 1.5 \\
Clean Clothes Campaign & 61 & 18.4 \\
Oeko-Tex Standard 100 & 12 & 3.6 \\
None of them & 126 & 38.0 \\
Missing & 3 & 0.9 \\
\hline
\end{tabular}

Table 9. Awareness of Common Textile Eco-Labels

\begin{tabular}{lcc}
\hline & Frequency & Percent \\
\hline Less than 5\% of my income & 75 & 22.6 \\
$5-10 \%$ of my income & 82 & 24.7 \\
10-15\% of my income & 63 & 19.0 \\
$15-20 \%$ of my income & 58 & 17.5 \\
$20-25 \%$ of my income & 26 & 7.8 \\
$25-30 \%$ of my income & 13 & 3.9 \\
More than 30\% of my income & 14 & 4.2 \\
Undisclosed & 1 & 0.3 \\
\hline
\end{tabular}

Table 10. Annual Expenditure on Clothing 
Influence of Income

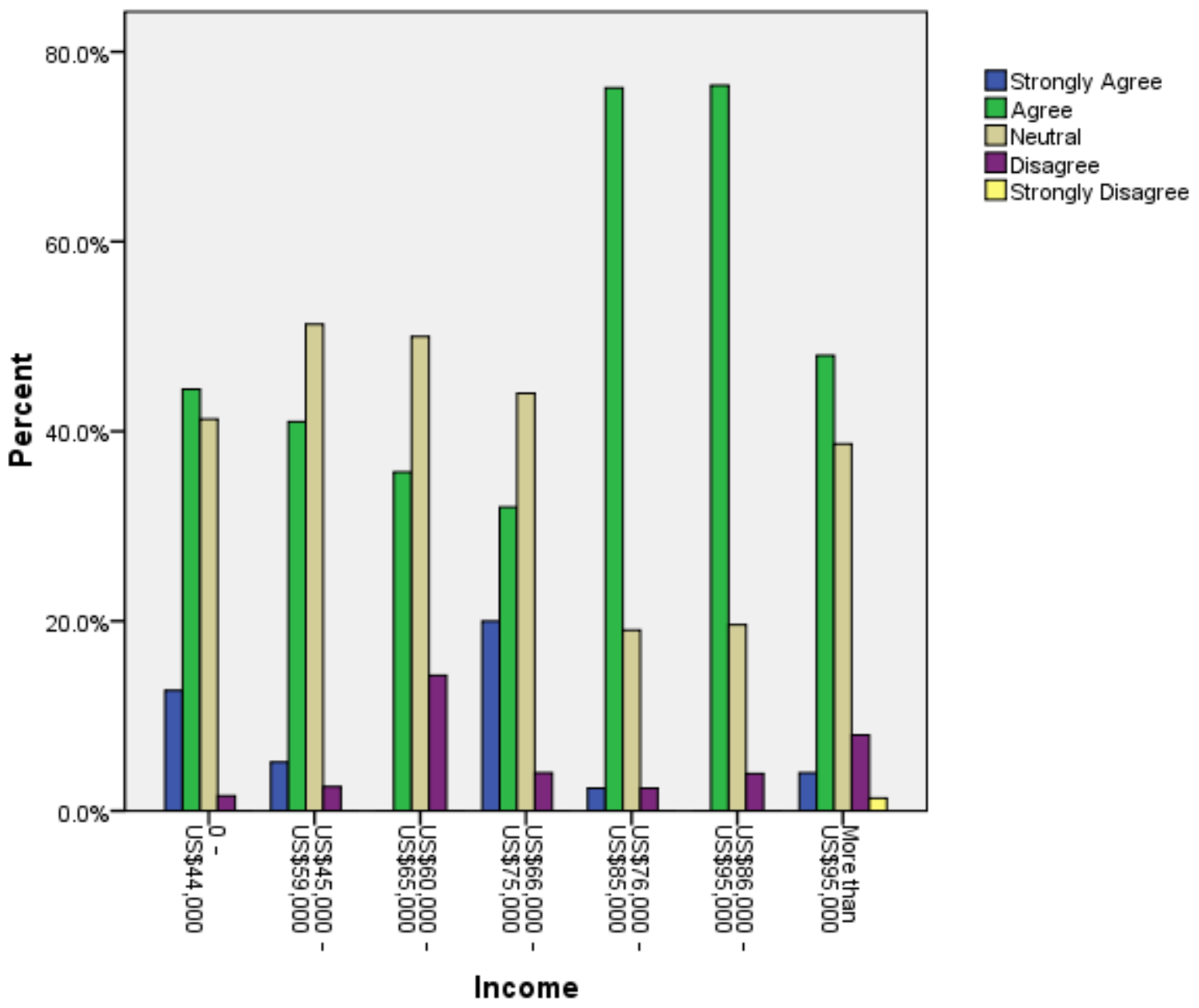

Figure 1. Income and Willingness to Buy Eco-Label Products

There was a $98 \%$ response rate to the question of income. It is interesting to note that a substantial portion of every income bracket respondents either did purchase or were fairly willing to purchase eco-label fashion products. Furthermore, the income brackets most likely to purchase eco-label products were those of $\$ 60,000$ to $\$ 75,000$ and $\$ 75,000$ to $\$ 95,000$; while the least likely buyers fell in the $\$ 60,000$ to $\$ 65,000$ and $\$ 66,000$ to $\$ 75,000$ income brackets. Meanwhile, there was very little difference in willingness to buy eco-label fashion products between members of the lowest 
bracket and members of the highest. From this data, then, it appears that income is not a strong influence on the purchase behavior about eco-label fashion products.

\section{Influence of Age}

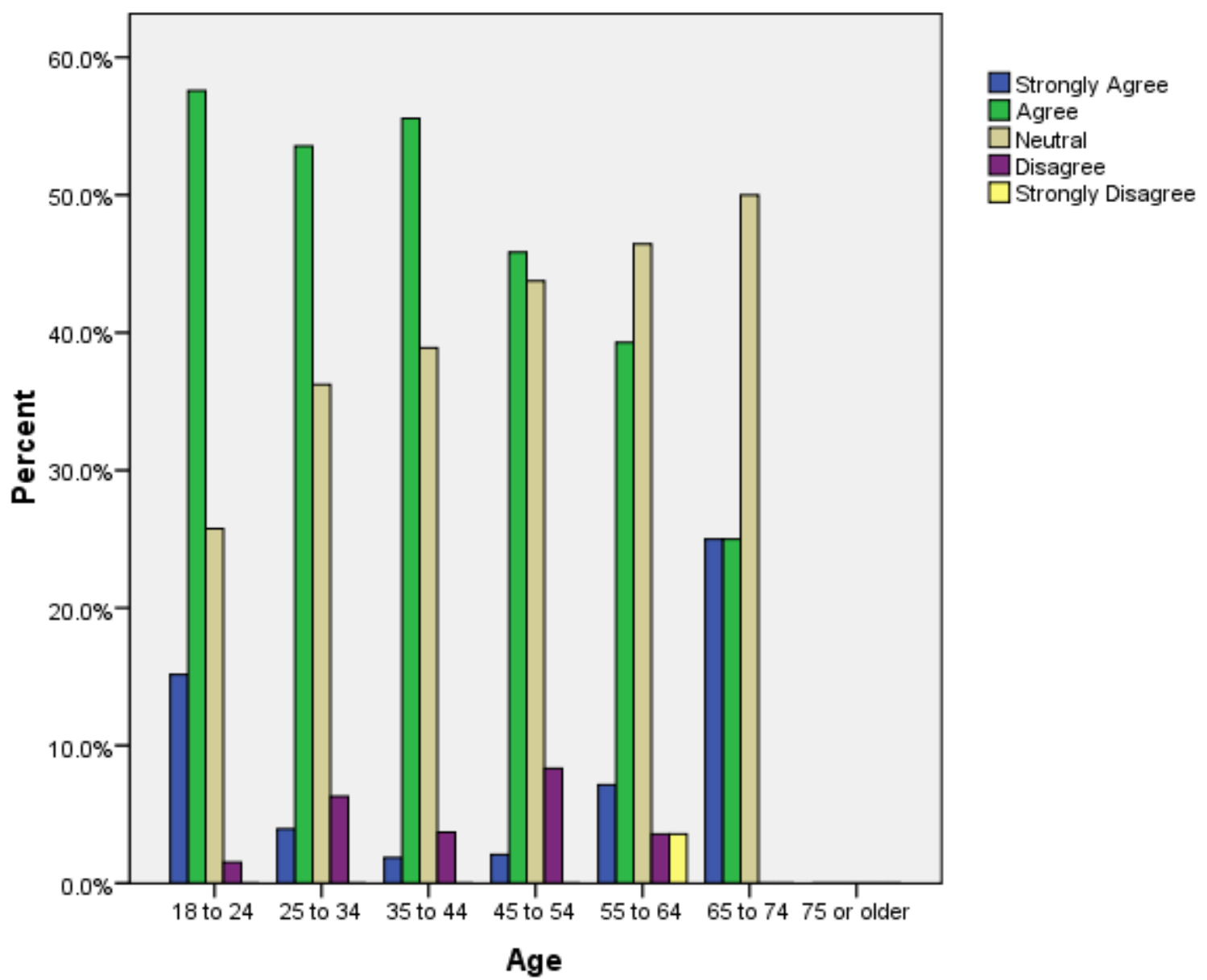

Figure 2. Age and Willingness to Buy Eco-Label Products

There was a $99 \%$ response rate to the question of age. According to responses, younger adults were the most willing to buy eco-label products. Around 55\% of the lowest three age brackets confirmed that they bought eco-label fashion products. Just less than half of those in middle-age (45 to 54 years) affirmed the same. Willingness decreased in the older brackets, with $40 \%$ of those 
between 55 and 64 and about a quarter of those between 65 and 74 admitting to purchasing ecolabel fashion products. While it is clear, based on these results, that age is inversely correlated with a willingness to buy eco-label fashions, it is fair to say that respondents of all ages are fairly willing to make such purchases.

\section{Influence of Education}

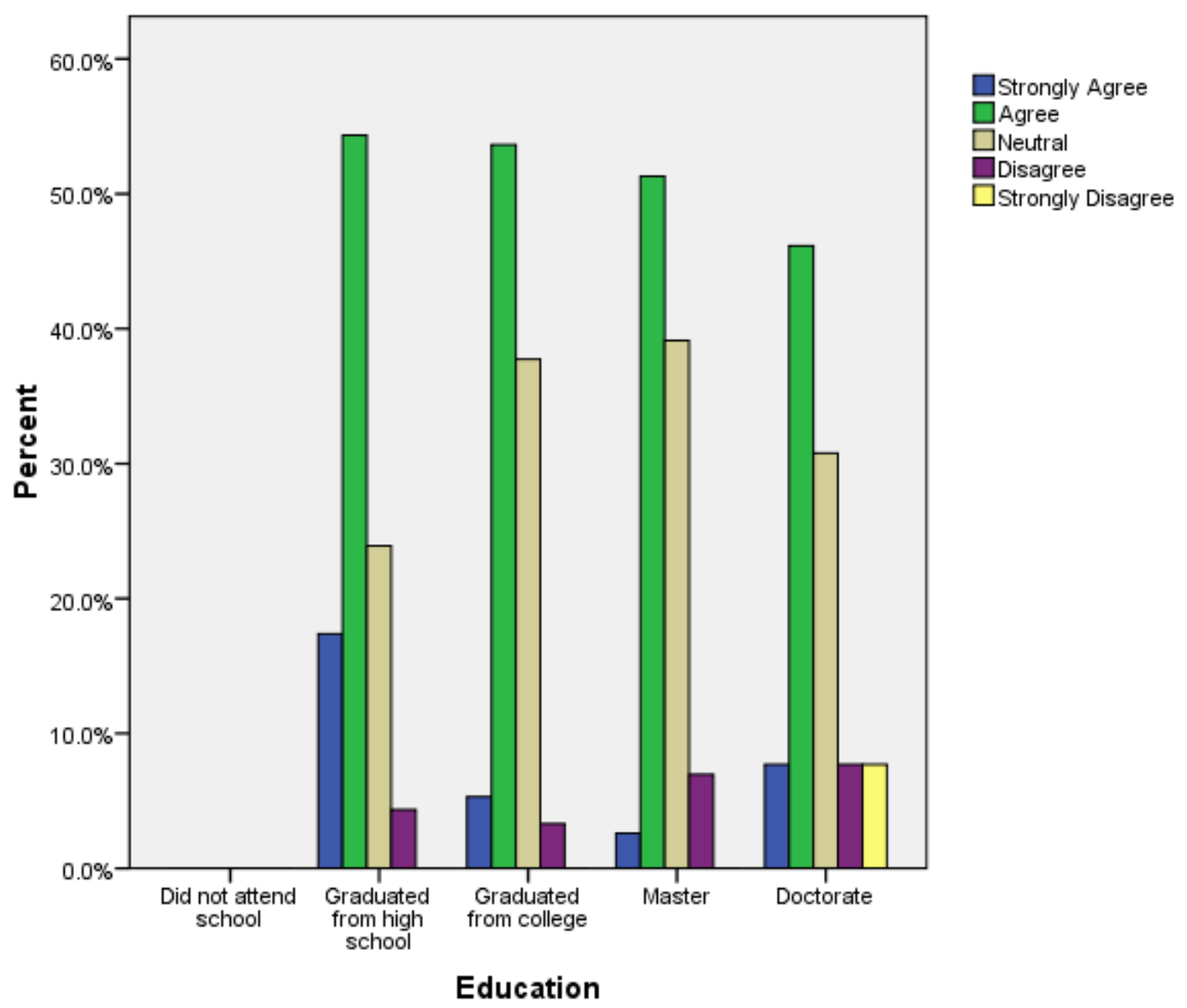

Figure 3. Education and Willingness to Buy Eco-Label Products

There was also a 99\% response rate to the question of level education, which showed minimal impact on respondents' purchasing behavior, with $45 \%$ to $55 \%$ of respondents at every level of education willing to purchase eco-label fashion products. Only a slight decrease in willingness is 
perceptible as degrees accrue, with 53\% of high school graduates and only $43 \%$ of PhDs willing to buy eco-label fashion products.

\section{Histograms}

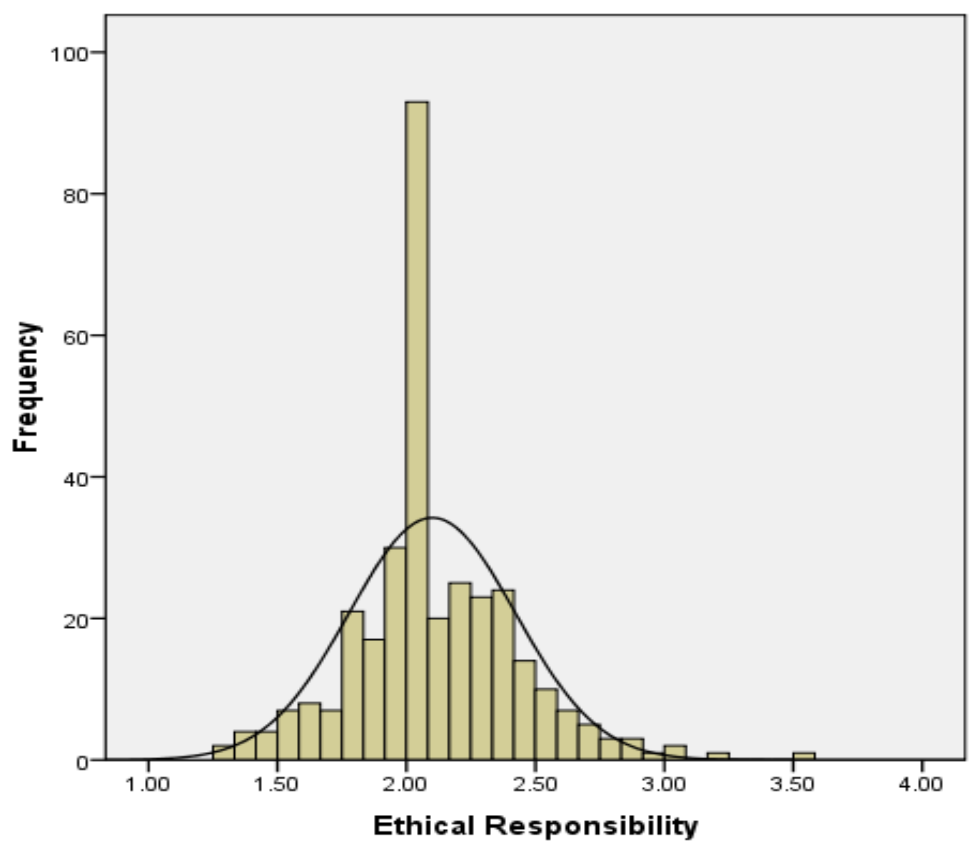

$\begin{aligned} \text { Mean } & =2.10 \\ \text { Std. Dev. } & =0.322\end{aligned}$

$\mathrm{N}=332$

Figure 4. Impact of Ethical Responsibility 


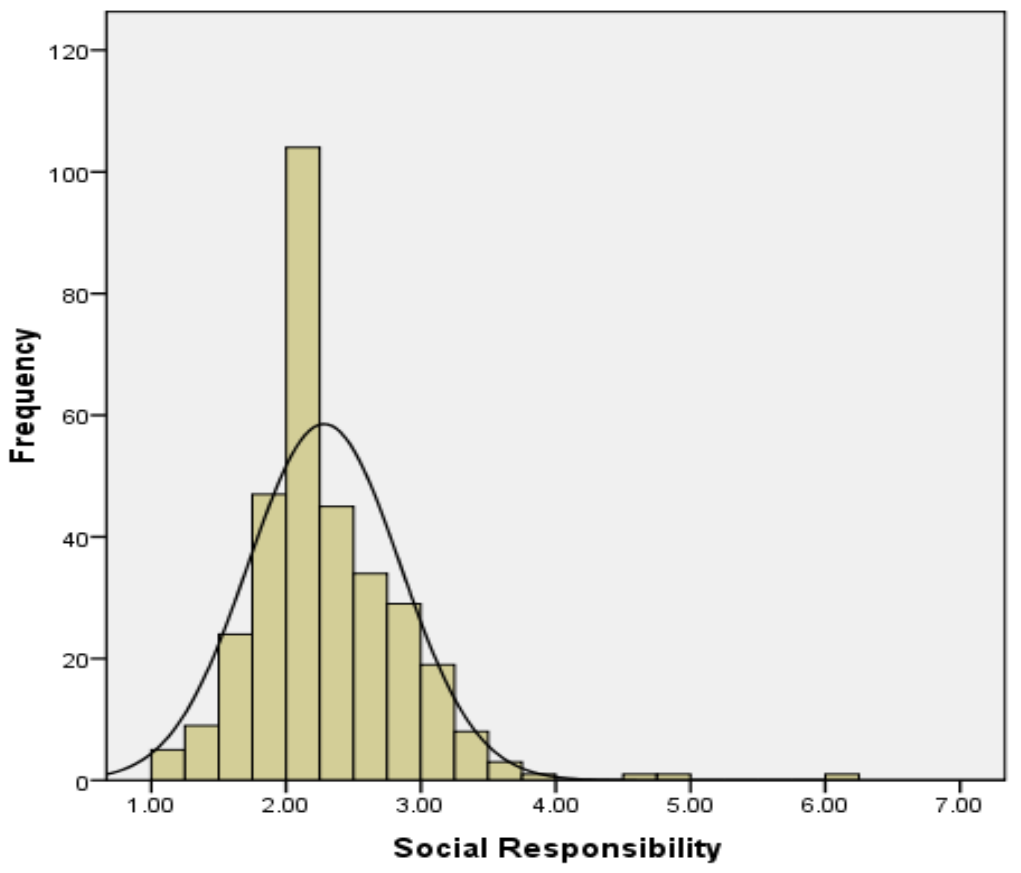

$\begin{aligned} \text { Mean } & =2.28 \\ \text { Std. Dev } & =0.564\end{aligned}$

$\mathrm{N}=331$

Figure 5. Impact of Social Responsibility

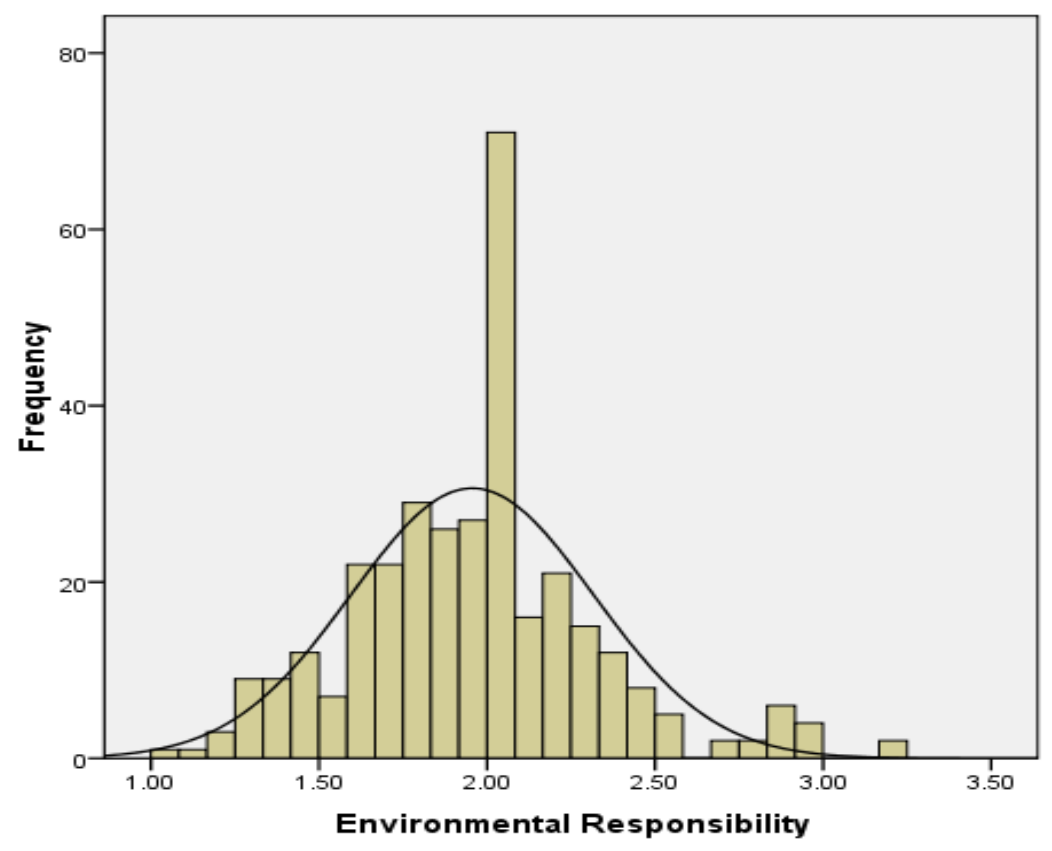

$\begin{aligned} \text { Mean } & =1.96 \\ \text { Std. Dev } & =0.36\end{aligned}$ $N=332$

Figure 6. Impact of Environmental Responsibility 


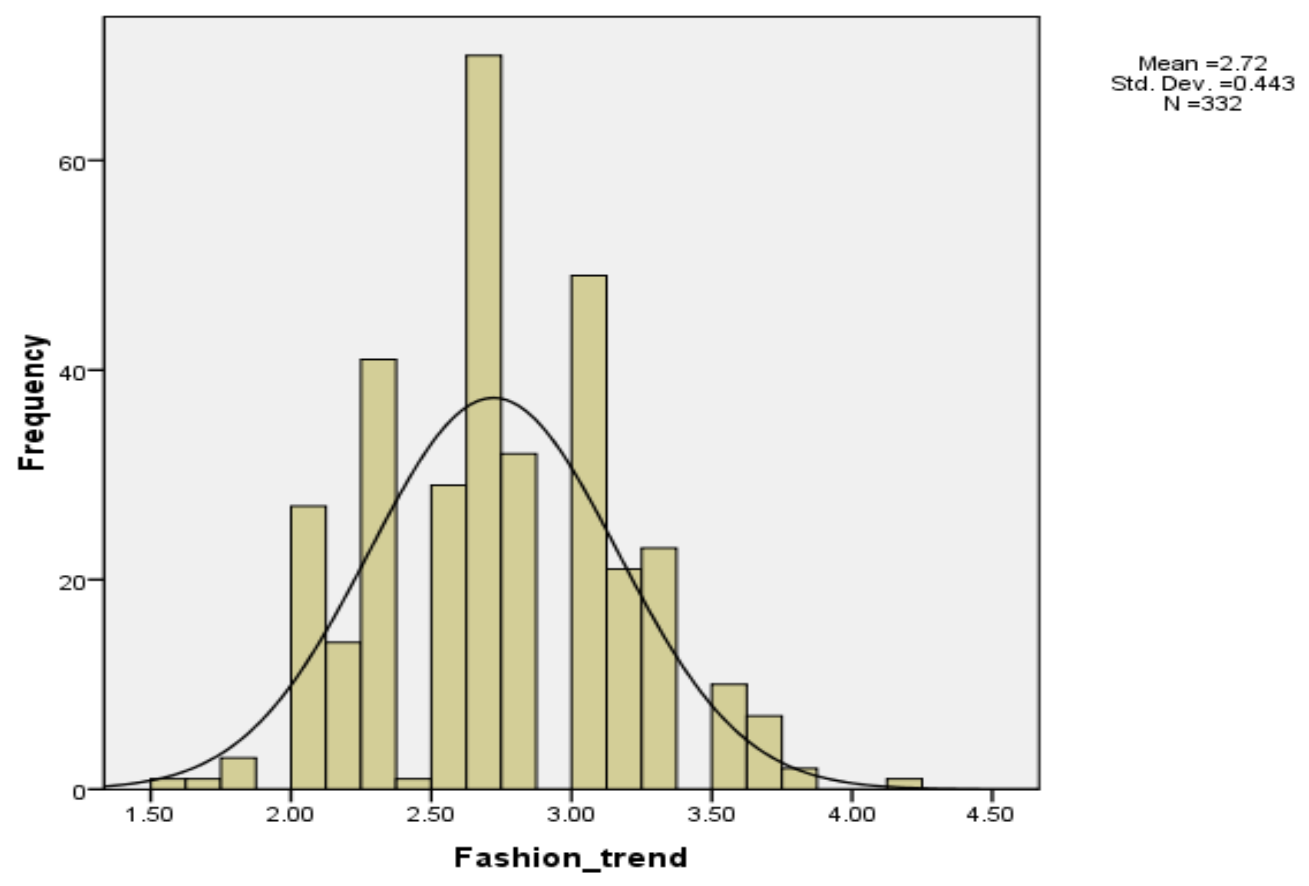

Figure 7. Impact of Fashion Trends

Figures 4, 5, 6, and 7 compare the impact of environmental responsibility, ethical responsibility, social responsibility, and fashion trends on purchasing behavior (where 1 is Very High/Strongly Agree and 5 is Very Low/Strongly Disagree). All histograms show normal curves; standard deviation for environmental responsibility (.332), ethical responsibility (.527), social responsibility (.360), and fashion trends (.443), being fairly distant from 1 , are relatively small and indicate that responses are reasonably consistent.Environmental responsibility had the most impact on respondents' purchases (at a mean response of 1.9, or High/Agree), but the average response for all four factors are quite similar (all around 2, or High/Agree, except for fashion trends, which appears to be a neutral effect).

These findings were checked against a frequency table (found in Appendix 1) for reliability. The frequency table showed that respondents were highly concerned about the environmental responsibility of their purchased clothing (74\%); about half were concerned equally with trends $(56 \%)$ and ethical responsibility (48\%); while only $30 \%$ considered social responsibility an 
important factor. It is perhaps interesting to see that fashion trends are not as important a factor in purchasing decisions as environmental consequences.

Based on the statistics above, it can be concluded that response level of environment responsibility is much higher than ethical and social responsibility while moderately less number of respondents consider social responsibility as an important factor during fashion related consumption.

\begin{tabular}{lccc}
\hline & Mean & Median & Mode \\
\hline Environmental Consciousness & 1.8644 & 2.0000 & 2.00 \\
Importance of Certification & 1.9804 & 2.0000 & 2.00 \\
Involvement in Certification & 2.2907 & 2.0000 & 2.00 \\
Willingness to pay & 2.6486 & 2.6667 & 2.00 \\
Purchase behavior & 1.9834 & 2.0000 & 2.00 \\
Commitment toward Eco-labels & 2.0226 & 2.0000 & 2.00 \\
Eco-label Fashion Product Pricing & 2.6717 & 2.6667 & 2.67 \\
Eco-label Fashion Product Quality & 2.7666 & 3.0000 & 3.00 \\
Brand Image & 2.6777 & 2.7500 & 2.50 \\
\hline
\end{tabular}

\section{Table 11. Statistics on Variables}

(where 1 is Very High/Strongly Agree and 5 is Very Low/Strongly Disagree)

Table 11 shows that environmental factors were on average the most important to people when considering eco-fashion purchases; environmental consciousness (on the part of the buyer) and environmental concern (on the part of the clothing brand) had the highest mean responses (1.8644 and 1.9834, i.e. High/Agree). Second most important were certifications and eco-labels (whether related or not to certifications), with average responses also of around 2, or High/Agree.

Conversely, price, perceived quality, and brand image were not felt in general to be strong motivators of eco-label purchases; mean and median responses tended closer to neutral (3). Prices of eco-label fashion products were perceived to be higher in general than non-eco-label products, perhaps contributing to more neutral attitudes towards these products; while the quality of eco- 
label fashion products was also perceived to be higher, but do not appear to encourage purchases either. It is arguable that strong environmental concerns are often mitigated by financial limitations.

\section{Analysis: Hypothesis Testing}

Purchasing Behavior (X9) and Importance of Certification (X2), Involvement in Certification (X3), Willingness to Pay (X4), and Commitment Toward Eco-labels (X5)

\begin{tabular}{lccccc}
\hline & $\begin{array}{c}\text { Purchasing } \\
\text { Behavior }\end{array}$ & $\begin{array}{c}\text { Importance } \\
\text { of } \\
\text { Certification }\end{array}$ & $\begin{array}{c}\text { Involvement } \\
\text { in } \\
\text { Certification }\end{array}$ & $\begin{array}{c}\text { Willingness } \\
\text { to Pay }\end{array}$ & $\begin{array}{c}\text { Commitment } \\
\text { toward Eco- } \\
\text { labels }\end{array}$ \\
\hline $\begin{array}{l}\text { Pearson Correlation } \\
\text { Sig. (2-tailed) }\end{array}$ & 1.000 & .103 & .433 & .414 & .476 \\
$\mathrm{~N}$ & & .160 & .000 & .008 & .000 \\
& 329 & 329 & 329 & 329 & 329 \\
\hline
\end{tabular}

Correlation is significant at the 0.05 level (2-tailed)

Table 12. Correlation Between Purchasing Behavior and Importance of Certification, Involvement in Certification, Willingness to Pay, and Commitment Toward Eco-labels

Between the importance of certification to the buyer, the retailer's involvement in certification, the buyer's willingness to pay and the retailer's commitment to eco-labels (whether certified or noncertified), all have a reliable relationship with purchasing behavior except for the importance of certification, which had a significance level far greater than 0.05 (.16) and a low Pearson value and therefore cannot be used in this study to predict purchasing behavior.The other three factors, however, show similarly and fairly positive relationships with purchasing behavior, with ecolabels exerting the most influence; respondents seem to be more likely to buy when clothes or companies either communicate or are perceived to be more environmentally friendly. 
H1: There is significant relationship between purchasing behavior and the importance of certification, brand involvement in certification, willingness to pay, and commitment towards ecolabels.

\begin{tabular}{llccccc}
\multicolumn{7}{c}{ ANOVA $^{\mathrm{b}}$} \\
\hline \multirow{2}{*}{ Model } & $\begin{array}{c}\text { Sum of } \\
\text { Squares }\end{array}$ & df & Mean Square & F & Sig. \\
\hline 1 & Regression & 44.843 & 4 & 11.211 & 31.605 & $.000^{\mathrm{a}}$ \\
& Residual & 115.282 & 325 & .355 & & \\
& Total & 160.124 & 329 & & & \\
\hline
\end{tabular}

a. Predictors: (Constant), Commitment toward Eco-labels, Importance of Certification, Willingness to Pay, Involvement in Certification

b. Dependent Variable: Purchasing Behavior

\section{Table 13. Significance Levels of the Regression Model: Purchasing Behavior According to Involvement in Certification, Importance of Certification, Commitment Toward Eco-labels and Willingness to Pay Combined}

According to the data from the regression analysis in the above table, the significance value is well below the window of explained variation (0.5), meaning that the combination of the four factors has a definitively positive correlation with purchasing behavior. It indicates that data support H1. Purchasing behavior can therefore be reliably predicted using the beta coefficients extracted via the regression model as shown in Table 14:

$$
\mathrm{X} 9=.979-.049 \times \mathrm{X} 2+.145 \times \mathrm{X} 3+.191 \times \mathrm{X} 4+.312 \times \mathrm{X} 5
$$

This model suggests that for every unit that commitment towards eco-labels increases (X6), willingness to purchase increases; while for every unit that willingness to pay (more) (X4) increases, willingness to purchases increases by .191 units; for every increase in involvement in certification (X3), willingness to purchase goes up by .145 units; and for every unit that importance 
of certification (X2) increases, willingness to purchase decreases by .049 units. However, as explained in the previous section, importance of certification is not a significant predictor of purchasing behavior as its Pearson value is greater than alpha $(.334>.05)$. With a beta coefficient of .312, eco-labels have the strongest influence on purchasing behavior.

Coefficients $^{\mathrm{a}}$

\begin{tabular}{|c|c|c|c|c|c|c|c|}
\hline & & & \multicolumn{2}{|c|}{$\begin{array}{l}\text { Unstandardized } \\
\text { Coefficients }\end{array}$} & \multirow{2}{*}{$\begin{array}{c}\begin{array}{c}\text { Standardized } \\
\text { Coefficients }\end{array} \\
\text { Beta }\end{array}$} & \multirow[b]{2}{*}{$\mathrm{t}$} & \multirow[b]{2}{*}{ Sig. } \\
\hline \multicolumn{3}{|c|}{ Model } & $\mathrm{B}$ & Std. Error & & & \\
\hline \multirow[t]{5}{*}{1} & (Constant) & & .979 & .166 & & 5.907 & .000 \\
\hline & $\begin{array}{l}\text { Importance of } \\
\text { Certification }\end{array}$ & $\mathrm{X} 2$ & -.068 & .070 & -.049 & -.967 & .334 \\
\hline & $\begin{array}{l}\text { Involvement in } \\
\text { Certification }\end{array}$ & $\mathrm{X} 3$ & .152 & .072 & .145 & 2.111 & .036 \\
\hline & Willingness to pay & $\mathrm{X} 4$ & .160 & .052 & .191 & 3.096 & .002 \\
\hline & $\begin{array}{l}\text { Commitment towar } \\
\text { Eco-labels }\end{array}$ & $\times 5$ & .395 & .073 & .312 & 5.422 & .000 \\
\hline
\end{tabular}

a. Dependent Variable: Purchasing Behavior

Table 14. Beta Coefficients of the Regression Model: Purchase Behavior According to Involvement in Certification and Importance of Certification

\begin{tabular}{ccccc}
\multicolumn{5}{c}{ Model Summary } \\
\hline Model & $\mathrm{R}$ & R & Adjusted R \\
& Squared & Squared & Std. Error of the Estimate \\
\hline 1 & $.521^{\mathrm{a}}$ & .272 & .263 & .515 \\
\hline
\end{tabular}

a. Predictors: (Constant), Commitment toward Eco-labels, Importance of Certification, Willingness to Pay, Involvement in Certification

Table15: Variation in Purchasing Behavior Explained by the Regression Model

The model summary (Table 15) shows a relatively low coefficient determination for the combined four factors $(\mathrm{R}$-squared $=.272)$, which means that less variance in the purchasing behavior can be 
predicted from them. More independent variables need to be considered to increase the predictive capability of the regression model.

From above tables, it is concluded that brand involvement in certification, willingness to pay, and commitment towards eco-labels are individually as well as together positively correlated with consumers' purchase behavior. However importance of certification is the only factor which does not have significant relationship with consumers' purchase behavior. Also, the four factors combined only explained $27 \%$ of variation in purchase behavior, which suggest including more variable for better predictive capability.

Environmental responsibility (10), Ethical responsibility (11), Social responsibility (12) and with Eco-labelling (14)

\begin{tabular}{|c|c|c|c|c|c|}
\hline \multicolumn{6}{|c|}{ Correlations } \\
\hline & & Eco-labelling & Environment & Social & Ethical \\
\hline \multirow{3}{*}{$\begin{array}{l}\text { Pearson } \\
\text { Correlation }\end{array}$} & Eco-labelling & 1.000 & .752 & .417 & .332 \\
\hline & Sig. (2-tailed) & .000 & .000 & .000 & .000 \\
\hline & $\mathrm{N}$ & 330 & 330 & 330 & 330 \\
\hline
\end{tabular}

Correlation is significant at the 0.05 level (2-tailed)

\section{Table 16: Correlation Between Eco-Labelling and Environmental Responsibility, Social Responsibility, Ethical Responsibility}

The results in Table 16 show that environmental responsibility, social responsibility and ethical responsibility have a positive and significant relationship with eco-labelling at a significance level of .000 , indicating that all these internal factors have a positive influence on the eco-labelling variable. Moreover, environmental responsibility appears to have the strongest correlation with eco-labelling, with a Pearson value of .752, compared with a value of .417 for social responsibility 
and .332 for ethical responsibility. Below, I further analyze how these factors combined affect consumers' purchasing behavior.

H2: There is a significant relationship between environmental responsibility, social responsibility, and ethical responsibility combined and eco-labelling.

\begin{tabular}{llccccc}
\multicolumn{7}{c}{ ANOVA $^{\mathrm{b}}$} \\
\hline \multicolumn{2}{l}{ Model } & $\begin{array}{c}\text { Sum of } \\
\text { Squares }\end{array}$ & df & Mean Square & F & Sig. \\
\hline 1 & Regression & 26.194 & 3 & 8.731 & 171.939 & $.000^{\mathrm{a}}$ \\
& Residual & 16.656 & 328 & .051 & & \\
& Total & 42.850 & 331 & & & \\
\hline
\end{tabular}

a. Predictors: (Constant), Ethic, Environment, and Social

Responsibility

b. Dependent Variable: Eco-labelling

Table17. Significance Levels of the Regression Model: Eco-labelling According to Environmental Responsibility, Social Responsibility, and Ethical Responsibility

The results in Table 17 confirm the hypothesis that environmental responsibility, social responsibility, and ethical responsibility severally and together have a significant impact on consumers' attention to eco-labelling, with a significance level of .000 . The degree of influence each independent variable has on the dependent variable of eco-labelling can be expressed with the following formula, using the beta coefficients from Table 18:

$$
\mathrm{X} 14=.459+.670 \times \mathrm{X} 10+.144 \times \mathrm{X} 14+.144 \times \mathrm{X} 15
$$




\begin{tabular}{|c|c|c|c|c|c|c|c|}
\hline \multicolumn{8}{|c|}{ Coefficients $^{\mathrm{a}}$} \\
\hline & & & \multicolumn{2}{|c|}{$\begin{array}{l}\text { Unstandardized } \\
\text { Coefficients }\end{array}$} & \multirow{2}{*}{$\begin{array}{c}\text { Standardized } \\
\text { Coefficients } \\
\text { Beta }\end{array}$} & \multirow[b]{2}{*}{$\mathrm{T}$} & \multirow[b]{2}{*}{ Sig. } \\
\hline \multicolumn{3}{|c|}{ Model } & $\mathrm{B}$ & Std. Error & & & \\
\hline \multirow[t]{4}{*}{1} & (Constant) & & .459 & .097 & & 4.713 & .000 \\
\hline & Environment & X10 & .669 & .037 & .670 & 18.069 & .000 \\
\hline & Ethic & X11 & .161 & .040 & .144 & 3.983 & .000 \\
\hline & Social & $\mathrm{X} 12$ & .096 & .025 & .144 & 3.834 & .000 \\
\hline
\end{tabular}

a. Dependent Variable: Eco-labelling

Table 18: Beta Coefficients of the Regression Model: Eco-lebelling According to Environmental Responsibility, Social Responsibility, and Ethical Responsibility

Environmental responsibility remains the most significant predictor of attention to eco-labelling, with abeta coefficient (.670) at significance level of .000 (Table 18). The adjusted R-squared in the model summary below (Table 19) indicates that $60.8 \%$ of the variation in attention to ecolabelling can be accounted for by environmental responsibility, social responsibility, and ethical responsibility combined.

\begin{tabular}{lcccc}
\hline \multicolumn{6}{c}{ Model Summary } \\
Model & R & $\begin{array}{c}\text { R- } \\
\text { Squared }\end{array}$ & $\begin{array}{c}\text { Adjusted R- } \\
\text { Squared }\end{array}$ & $\begin{array}{l}\text { Std. Error of } \\
\text { the Estimate }\end{array}$ \\
\hline 1 & $.782^{\mathrm{a}}$ & .611 & \multicolumn{6}{c}{.608} & .22535 \\
\hline a. Predictors: (Constant), Ethic, Environment, Social
\end{tabular}

\section{Table19. The Number of Variation in Eco-Labelling Explained by the Regression Model}

From the above tables, it is concluded that environmental responsibility, social responsibility, and ethical responsibility are separately as well as together positively related to eco-labelling. Environmental responsibility appears to have the strongest correlation with eco-labelling. Also, these three internal factors combined explain reasonable (60\%) variation in eco-labelling, which suggest these variables are good to predict consumers' purchase behavior toward eco-labelling. 
Purchasing Behavior (X9) and Environmental responsibility (X10), Ethical responsibility (X11), Social $\underline{\text { responsibility (X12) and Fashion trends (X13) }}$

Correlations

\begin{tabular}{llccccc}
\hline & & $\begin{array}{c}\text { Purchasing } \\
\text { behavior }\end{array}$ & Environment & Social & Ethic & Fashion \\
\hline Purchasing & Pearson Correlation & 1 & $.407^{* *}$ & $.305^{* *}$ & $.260^{* *}$ & -.043 \\
behavior & Sig. (2-tailed) & & .000 & .000 & .000 & .440 \\
& $\mathrm{~N}$ & 330 & 330 & 330 & 330 & 330 \\
\hline
\end{tabular}

** Correlation is significant at the 0.05 level (2-tailed).

Table20: Correlation Between Purchasing Behavior and Environmental Responsibility, Social Responsibility, Ethical Responsibility, and Fashion Trends

The independent variables in this section consist of the previous three variables with the addition of fashion trends. Table 20 shows the individual correlation of environmental responsibility, social responsibility, ethical responsibility and fashion trends with consumers' purchasing behavior. Among these four factors, the only factor that on its own does not have a significant relationship with purchasing behavior is fashion trend; its significance value is far above the window of explained variance $(.440>.05)$. This indicates that fashion trends in general do not have a significant impact on consumers' purchases of items with eco-labels; indeed, they may be irrelevant when it comes to eco-label purchases, since eco-label products usually have their own aesthetic. This finding may be related to earlier discussion in this study - brand image is an important factor for consumers when it's come to fashion apparel purchasing, and eco-label products introduced by brands are little costly for most of the consumers (as discussed in the literature chapter). The other three factors remain strongly correlated with purchasing behavior.

H3: There is a significant relationship between environmental responsibility and purchasing behavior.

H4: There is a significant relationship between social responsibility and purchasing behavior.

H5: There is a significant relationship between ethical responsivity and purchasing behavior.

H6: There is a significant relationship between fashion trends and purchasing behavior. 
ANOVA $^{\mathrm{b}}$

\begin{tabular}{llccccc}
\hline \multicolumn{1}{l}{ Model } & & $\begin{array}{c}\text { Sum of } \\
\text { Squares }\end{array}$ & df & Mean Square & F & Sig. \\
\hline 1 & Regression & 35.518 & 4 & 8.879 & 23.159 & $.000^{\mathrm{a}}$ \\
& Residual & 124.607 & 325 & .383 & & \\
& Total & 160.124 & 329 & & & \\
\hline
\end{tabular}

a. Predictors: (Constant), Fashion, Ethic, Environment, Social

b. Dependent Variable: Purchasing behavior

Table 21. Significance Levels of the Regression Model: Purchasing BehaviorAccording to Environmental Responsibility, Social Responsibility, Ethical Responsibility, and Fashion Trends

The results in Table21 show that environmental responsibility, social responsibility, ethical responsibility and fashion trends together relate significantly to consumers' purchasingbehavior, at a significance level of .000 . The combined effect of these variables on purchasing behavior can be expressed with the following regression formulation using beta coefficients from Table 22:

$$
\mathrm{X} 9=.416+.328 \times \mathrm{X} 10+.157 \times \mathrm{X} 11+.143 \times \mathrm{X} 12-.080 \times \mathrm{X} 13
$$

Coefficients $^{\mathrm{a}}$

\begin{tabular}{|c|c|c|c|c|c|c|c|}
\hline \multirow{2}{*}{\multicolumn{3}{|c|}{ Model }} & \multicolumn{2}{|c|}{$\begin{array}{l}\text { Unstandardized } \\
\text { Coefficients }\end{array}$} & \multirow{2}{*}{$\begin{array}{c}\text { Standardized } \\
\text { Coefficients } \\
\text { Beta }\end{array}$} & \multirow[b]{2}{*}{$\mathrm{t}$} & \multirow[b]{2}{*}{ Sig. } \\
\hline & & & B & Std. Error & & & \\
\hline \multirow[t]{5}{*}{1} & (Constant) & & .416 & .337 & & 1.235 & .218 \\
\hline & Environment & $\mathrm{X} 10$ & .633 & .102 & .328 & 6.202 & .000 \\
\hline & Ethic & $\mathrm{X} 11$ & .311 & .112 & .143 & 2.778 & .006 \\
\hline & Social & $\mathrm{X} 12$ & .202 & .069 & .157 & 2.934 & .004 \\
\hline & Fashion & $\mathrm{X} 13$ & -.114 & .070 & -.080 & -1.624 & .105 \\
\hline
\end{tabular}

a. Dependent Variable: Purchasing behavior

Table 22. Beta Coefficients of the Regression Model: Purchasing Behavior According to Environmental Responsibility, Social Responsibility, Ethical Responsibility, and Fashion Trends 
The numbers in Table 22 confirm that environmental responsibility, social responsibility, and ethical responsibility when combined are also significant predictors of consumers' purchasingecolabel, with significance levelsof $.000, .004$, and .006 respectively. It can be concluded that H3, H4 and H5 are valid. The beta coefficient of fashion trends is too high $(.105>.05)$, reaffirming that it is not a good predictor of eco-label fashion products; the data does not support H6.

\begin{tabular}{lcccc}
\hline \multicolumn{4}{c}{ Model Summary } \\
Model & $\mathrm{R}$ & $\begin{array}{c}\mathrm{R}- \\
\text { Squared }\end{array}$ & $\begin{array}{c}\text { Adjusted R- } \\
\text { Squared }\end{array}$ & $\begin{array}{c}\text { Std. Error of } \\
\text { the Estimate }\end{array}$ \\
\hline 1 & $.471^{\mathrm{a}}$ & .222 & .212 & .619 \\
\hline \multicolumn{4}{l}{ a. Predictors: (Constant), Fashion, Ethic, Environment, Social }
\end{tabular}

Table 23. Variation in Purchasing Behavior Explained by the Regression Model

The adjusted R-squared in the model summary (table 23) indicates thatonly $21.2 \%$ of the variation in purchasing behavior can be accounted for by environmental responsibility, social responsibility, ethical responsibility and fashion trends together. Therefore, more independent variables need to be incorporated to increase the predictive capability of the regression model.

From the above tables, it is concluded that environmental responsibility, social responsibility, and ethical responsibility are correlated individually and together with Purchase behavior. Fashion trend is only factor which does not have significant influence on consumers' purchase behavior regarding eco-labelling. $21.2 \%$ of the variation in purchase behavior can be expressed by these four internal factors. Therefore, it suggests further research to continue looking up other independent variables that might help to better explain consumers' purchase behavior toward ecolabelling. 


\title{
Chapter Five
}

\author{
Conclusions
}

\section{Conclusion}

The primary goal of Eco-labels is to promote the consumer knowledge about the positive features of environmentally-friendly products and to guide them toward purchasing such products. To understand eco-label's function in actual circumstances, studying consumers' purchasing behavior toward eco-labelling can help companies, organizations and governments to make better policies regarding eco-friendly products. By understanding consumers' purchasing behavior companies can determine whether the function of eco-labels is effective as a communication instrument for eco-label products. Myriad research has been conducted to understand eco-labels, whereas limited investigation has been done about the consumers' purchasing behavior in relation to eco-friendly products. This study therefore focuses on the consumers' purchase behavior toward fashion related eco-label products.

The purpose of the study is to understand fashion consumers' purchasing behavior toward eco-labelling with respect to four factors: the current fashion system, environmental responsibility, ethical responsibility, and social responsibility. The relationship between these four factors together with eco-labelling and with purchasing behavior is successfully tested. Moreover, correlation between these four factors was also separately checked with consumers' purchasing behavior. Factors like importance of certification, environmental concern, willingness to buy ecolabel products, quality of eco-label products, price of eco-label products and brand image were also analyzed in the study for deeper insight into consumers' purchase behavior. The influence of demographic characteristics on consumers' purchasing behavior is also determined in this study. 
The study shows that young consumers were relatively more willing to buy environmentally-friendly products. It has been also found that education level, and gender does not have strong influence on buying eco-friendly products. Respondents were highly concerned about the protection of the environment and hence willing to reduce their consumption and avoid buying environmentally-harmful products. Respondents considered certified eco-label products helpful in making purchasing decisions regarding fashion related products. Brand image and quality of product were considered an important factor for buying fashion apparel. Respondents are willing to buy eco-label products despite of their high price. Difference in consumer income level was found to be insignificant; this differs from the theory, which suggests that fashion-related eco-friendly products are bought by a faction of consumers with high income. As per the findings of the study, the respondents in the study did not have enough knowledge about popular textile eco-labels. The study shows that most of the respondents ( 24.7 percent) spend "5 to 10 percent" of their income on clothing per year.

The results show that 48 percent of respondents were highly concerned about ethical responsibility and 30 percent of respondents reported that social responsibility was an important factor while buying fashion related products. 56 percent of respondents reported that they were highly concerned about latest fashion trends and were interested enough to buy the latest fashion products. 73 percent of respondents were highly concerned about environmental responsibility while shopping for fashion-related products.

The study confirms that the relation between involvement in certification and importance of certification, commitment toward eco-labels and willingness to pay, significantly relate to consumers' purchasing behavior. The study shows that environmental responsibility, social 
responsibility and ethical responsibility have positive and significant relationships with ecolabelling and consumers' purchase behavior. Fashion trends do not have significant influence on consumers' purchase behavior regarding eco-labelling. This finding may be related to the earlier discussion of brand image as an important factor for consumers when it comes to fashion apparel purchasing, and that eco-label products introduced by brands are consider too costly for most consumers.

Generally, from the above discussion it is concluded that eco-labels do influence consumers' buying behavior. Eco-labels help consumers to make their decision faster, and distinguish those products that they want to buy from the other ordinary products. From the survey result it is possible to conclude that eco-friendly purchasing is complicated as people must consider a lot of factors before buying: product price, quality, assurance of eco-friendliness and last but the least, where to find such products. It is found in the study that people were satisfied with ecofriendly purchasing and hence willing to buy environmentally-friendly products.

\section{Limitation of the Research}

The study is not without its share of limitations. The data collected for this study has no geographic constrains, which makes the context of this study relatively large, but the sample size of 332 is quite small for the representation of such a large context. For generalization and greater accuracy of the results, it is recommended to repeat the same study with a larger sample size.

The demographic ground of selecting the sample is convenience sampling, which represents the views of a specific group and not the entire population. Results derived from convenience sampling cannot generalize the conclusions drawn from the research as applicable to the whole population. Results of this study suggest that more independent variables are required to more deeply understand consumers' purchase behavior. Income, age and country of residence have not been 
tested successfully in this study and thus further demand other research to cover these factors as influence factors.

The purpose of eco-labelling is to encourage the demand and supply of those products and services that cause less harm to the environment. This study has revealed how eco-labels affects consumers' purchasing behavior and knowledge about their environmental responsibility, social responsibility, ethical responsibility and latest fashion trends. The findings have highlighted that eco-labels play an important role in consumers purchasing behavior as it helps them to choose products which are not harmful for environment and that they are willing to pay more for such products. The study has also developed accurate data on demographics, behaviors, and the relationship between internal four factors (environmental responsibility, social responsibility, ethical responsibility and latest fashion trends). It is found that consumers are satisfied with their eco-consumption and willing to buy these products in the future as well. Supported by these findings it is hoped that despite the complexities, companies improve the sales and image of eco-label products. 


\section{Appendix A}

Frequency tables of Environmental responsibility, Social responsibility, Ethical responsibility and Fashion trend

Table A1

Fashion Trend

\begin{tabular}{|c|c|c|c|c|c|}
\hline \multirow{2}{*}{ Valid } & & Frequency & Percent & \multicolumn{2}{|r|}{$\begin{array}{c}\text { Cumulative } \\
\text { Percent }\end{array}$} \\
\hline & 1.83 & 1 & .3 & .3 & .3 \\
\hline & 2 & 9 & 2.7 & 2.7 & 3.0 \\
\hline & 2.17 & 8 & 2.4 & 2.4 & 5.4 \\
\hline & 2.33 & 12 & 3.6 & 3.6 & 9.0 \\
\hline & 2.4 & 1 & .3 & .3 & 9.3 \\
\hline & 2.5 & 25 & 7.5 & 7.5 & 16.9 \\
\hline & 2.67 & 45 & 13.6 & 13.6 & 30.4 \\
\hline & 2.83 & 30 & 9.0 & 9.0 & 39.5 \\
\hline & 3 & 57 & 17.2 & 17.2 & 56.6 \\
\hline & 3.17 & 25 & 7.5 & 7.5 & 64.2 \\
\hline & 3.2 & 1 & .3 & .3 & 64.5 \\
\hline & 3.33 & 28 & 8.4 & 8.4 & 72.9 \\
\hline & 3.5 & 25 & 7.5 & 7.5 & 80.4 \\
\hline & 3.6 & 2 & .6 & .6 & 81.0 \\
\hline & 3.67 & 51 & 15.4 & 15.4 & 96.4 \\
\hline & 3.83 & 3 & .9 & .9 & 97.3 \\
\hline & 4 & 7 & 2.1 & 2.1 & 99.4 \\
\hline & 4.17 & 2 & .6 & .6 & 100.0 \\
\hline & Total & 332 & 100.0 & 100.0 & \\
\hline
\end{tabular}


Table A2

Ethical Responsibility

\begin{tabular}{cccccc}
\hline & & & & Cumulative \\
Valid & & Frequency & Percent & Valid Percent & Percent \\
\hline 1.31 & 1 & .3 & .3 & .3 \\
1.33 & 1 & .3 & .3 & .6 \\
1.38 & 4 & 1.2 & 1.2 & 1.8 \\
1.46 & 4 & 1.2 & 1.2 & 3.0 \\
1.54 & 7 & 2.1 & 2.1 & 5.1 \\
1.62 & 8 & 2.4 & 2.4 & 7.5 \\
1.69 & 7 & 2.1 & 2.1 & 9.6 \\
1.77 & 21 & 6.3 & 6.3 & 16.0 \\
1.85 & 17 & 5.1 & 5.1 & 21.1 \\
1.92 & 30 & 9.0 & 9.0 & 30.1 \\
2 & 62 & 18.7 & 18.7 & 48.8 \\
2.08 & 31 & 9.3 & 9.3 & 58.1 \\
2.15 & 20 & 6.0 & 6.0 & 64.2 \\
2.17 & 1 & .3 & .3 & 64.5 \\
2.23 & 24 & 7.2 & 7.2 & 71.7 \\
2.25 & 1 & .3 & .3 & 72.0 \\
2.31 & 22 & 6.6 & 6.6 & 78.6 \\
2.33 & 1 & .3 & .3 & 78.9 \\
2.38 & 23 & 6.9 & 6.9 & 85.8 \\
2.42 & 1 & .3 & .3 & 86.1 \\
2.46 & 13 & 3.9 & 3.9 & 90.1 \\
2.5 & 1 & .3 & .3 & 90.4 \\
2.54 & 9 & 2.7 & 2.7 & 93.1 \\
2.58 & 1 & .3 & .3 & 93.4 \\
2.62 & 6 & 1.8 & 1.8 & 95.2 \\
2.69 & 5 & 1.5 & 1.5 & 96.7 \\
2.77 & 3 & .9 & .9 & 97.6 \\
2.85 & 3 & .9 & .9 & 98.5 \\
2.92 & 1 & .3 & .3 & 98.8 \\
3 & 2 & .6 & .6 & 99.4 \\
3.23 & 1 & .3 & .3 & 99.7 \\
3.54 & 1 & .3 & .3 & 100.0 \\
Total & 332 & 100.0 & 100.0 & \\
\hline & & & &
\end{tabular}


Table A3

Social Responsibility

\begin{tabular}{|c|c|c|c|c|c|}
\hline \multirow{2}{*}{ Valid } & & Frequency & Percent & Valid Percent & $\begin{array}{c}\text { Cumulative } \\
\text { Percent }\end{array}$ \\
\hline & 0 & 1 & .3 & .3 & .3 \\
\hline & 1.11 & 2 & .6 & .6 & .9 \\
\hline & 1.22 & 3 & .9 & .9 & 1.8 \\
\hline & 1.33 & 1 & .3 & .3 & 2.1 \\
\hline & 1.44 & 8 & 2.4 & 2.4 & 4.5 \\
\hline & 1.56 & 6 & 1.8 & 1.8 & 6.3 \\
\hline & 1.67 & 18 & 5.4 & 5.4 & 11.7 \\
\hline & 1.78 & 20 & 6.0 & 6.0 & 17.8 \\
\hline & 1.88 & 1 & .3 & .3 & 18.1 \\
\hline & 1.89 & 26 & 7.8 & 7.8 & 25.9 \\
\hline & 2 & 40 & 12.0 & 12.0 & 38.0 \\
\hline & 2.11 & 44 & 13.3 & 13.3 & 51.2 \\
\hline & 2.22 & 20 & 6.0 & 6.0 & 57.2 \\
\hline & 2.25 & 1 & .3 & .3 & 57.5 \\
\hline & 2.33 & 22 & 6.6 & 6.6 & 64.2 \\
\hline & 2.38 & 1 & .3 & .3 & 64.5 \\
\hline & 2.44 & 21 & 6.3 & 6.3 & 70.8 \\
\hline & 2.5 & 1 & .3 & .3 & 71.1 \\
\hline & 2.56 & 19 & 5.7 & 5.7 & 76.8 \\
\hline & 2.67 & 14 & 4.2 & 4.2 & 81.0 \\
\hline & 2.75 & 1 & .3 & .3 & 81.3 \\
\hline & 2.78 & 17 & 5.1 & 5.1 & 86.4 \\
\hline & 2.89 & 11 & 3.3 & 3.3 & 89.8 \\
\hline & 3 & 10 & 3.0 & 3.0 & 92.8 \\
\hline & 3.11 & 5 & 1.5 & 1.5 & 94.3 \\
\hline & 3.22 & 5 & 1.5 & 1.5 & 95.8 \\
\hline & 3.33 & 4 & 1.2 & 1.2 & 97.0 \\
\hline & 3.44 & 4 & 1.2 & 1.2 & 98.2 \\
\hline & 3.56 & 1 & .3 & .3 & 98.5 \\
\hline & 3.67 & 2 & .6 & .6 & 99.1 \\
\hline & 3.78 & 1 & .3 & .3 & 99.4 \\
\hline & 4.56 & 1 & .3 & .3 & 99.7 \\
\hline & 4.89 & 1 & .3 & .3 & 100.0 \\
\hline & Total & 332 & 100.0 & 100.0 & \\
\hline
\end{tabular}


Table A4

Environmental Responsibility

\begin{tabular}{|c|c|c|c|c|c|}
\hline & & Frequency & Percent & Valid Percent & $\begin{array}{c}\text { Cumulative } \\
\text { Percent }\end{array}$ \\
\hline \multirow[t]{40}{*}{ Valid } & 1 & 1 & .3 & .3 & .3 \\
\hline & 1.11 & 1 & .3 & .3 & .6 \\
\hline & 1.18 & 1 & .3 & .3 & .9 \\
\hline & 1.2 & 1 & .3 & .3 & 1.2 \\
\hline & 1.24 & 1 & .3 & .3 & 1.5 \\
\hline & 1.27 & 1 & .3 & .3 & 1.8 \\
\hline & 1.29 & 1 & .3 & .3 & 2.1 \\
\hline & 1.3 & 1 & .3 & .3 & 2.4 \\
\hline & 1.31 & 1 & .3 & .3 & 2.7 \\
\hline & 1.33 & 5 & 1.5 & 1.5 & 4.2 \\
\hline & 1.36 & 2 & .6 & .6 & 4.8 \\
\hline & 1.37 & 1 & .3 & .3 & 5.1 \\
\hline & 1.39 & 2 & .6 & .6 & 5.7 \\
\hline & 1.4 & 3 & .9 & .9 & 6.6 \\
\hline & 1.41 & 1 & .3 & .3 & 6.9 \\
\hline & 1.42 & 4 & 1.2 & 1.2 & 8.1 \\
\hline & 1.43 & 1 & .3 & .3 & 8.4 \\
\hline & 1.44 & 5 & 1.5 & 1.5 & 9.9 \\
\hline & 1.47 & 2 & .6 & .6 & 10.5 \\
\hline & 1.51 & 1 & .3 & .3 & 10.8 \\
\hline & 1.52 & 1 & .3 & .3 & 11.1 \\
\hline & 1.53 & 2 & .6 & .6 & 11.7 \\
\hline & 1.56 & 1 & .3 & .3 & 12.0 \\
\hline & 1.58 & 2 & 6 & .6 & 12.7 \\
\hline & 1.59 & 2 & .6 & .6 & 13.3 \\
\hline & 1.6 & 3 & .9 & .9 & 14.2 \\
\hline & 1.61 & 5 & 1.5 & 1.5 & 15.7 \\
\hline & 1.63 & 3 & .9 & .9 & 16.6 \\
\hline & 1.64 & 4 & 1.2 & 1.2 & 17.8 \\
\hline & 1.66 & 5 & 1.5 & 1.5 & 19.3 \\
\hline & 1.67 & 4 & 1.2 & 1.2 & 20.5 \\
\hline & 1.69 & 6 & 1.8 & 1.8 & 22.3 \\
\hline & 1.7 & 2 & .6 & .6 & 22.9 \\
\hline & 1.71 & 1 & .3 & .3 & 23.2 \\
\hline & 1.72 & 5 & 1.5 & 1.5 & 24.7 \\
\hline & 1.73 & 4 & 1.2 & 1.2 & 25.9 \\
\hline & 1.76 & 2 & .6 & .6 & 26.5 \\
\hline & 1.77 & 1 & .3 & .3 & 26.8 \\
\hline & 1.78 & 2 & .6 & .6 & 27.4 \\
\hline & 1.8 & 15 & 4.5 & 4.5 & 31.9 \\
\hline
\end{tabular}




\begin{tabular}{|c|c|c|c|c|}
\hline 1.81 & 2 & .6 & .6 & 32.5 \\
\hline 1.82 & 4 & 1.2 & 1.2 & 33.7 \\
\hline 1.83 & 3 & .9 & .9 & 34.6 \\
\hline 1.84 & 2 & .6 & .6 & 35.2 \\
\hline 1.86 & 3 & .9 & .9 & 36.1 \\
\hline 1.87 & 10 & 3.0 & 3.0 & 39.2 \\
\hline 1.88 & 1 & .3 & .3 & 39.5 \\
\hline 1.89 & 2 & .6 & .6 & 40.1 \\
\hline 1.9 & 4 & 1.2 & 1.2 & 41.3 \\
\hline 1.91 & 4 & 1.2 & 1.2 & 42.5 \\
\hline 1.93 & 19 & 5.7 & 5.7 & 48.2 \\
\hline 1.94 & 1 & .3 & .3 & 48.5 \\
\hline 1.96 & 4 & 1.2 & 1.2 & 49.7 \\
\hline 1.97 & 1 & .3 & .3 & 50.0 \\
\hline 1.98 & 2 & .6 & .6 & 50.6 \\
\hline 2 & 53 & 16.0 & 16.0 & 66.6 \\
\hline 2.02 & 2 & .6 & .6 & 67.2 \\
\hline 2.03 & 3 & .9 & .9 & 68.1 \\
\hline 2.04 & 1 & .3 & .3 & 68.4 \\
\hline 2.06 & 3 & .9 & .9 & 69.3 \\
\hline 2.07 & 8 & 2.4 & 2.4 & 71.7 \\
\hline 2.08 & 1 & .3 & .3 & 72.0 \\
\hline 2.09 & 2 & .6 & .6 & 72.6 \\
\hline 2.1 & 3 & .9 & .9 & 73.5 \\
\hline 2.11 & 2 & .6 & .6 & 74.1 \\
\hline 2.12 & 1 & .3 & .3 & 74.4 \\
\hline 2.13 & 5 & 1.5 & 1.5 & 75.9 \\
\hline 2.14 & 1 & .3 & .3 & 76.2 \\
\hline 2.16 & 2 & .6 & .6 & 76.8 \\
\hline 2.17 & 3 & .9 & .9 & 77.7 \\
\hline 2.18 & 4 & 1.2 & 1.2 & 78.9 \\
\hline 2.2 & 3 & .9 & .9 & 79.8 \\
\hline 2.21 & 4 & 1.2 & 1.2 & 81.0 \\
\hline 2.22 & 3 & .9 & .9 & 81.9 \\
\hline 2.24 & 4 & 1.2 & 1.2 & 83.1 \\
\hline 2.26 & 1 & .3 & .3 & 83.4 \\
\hline 2.27 & 5 & 1.5 & 1.5 & 84.9 \\
\hline 2.28 & 4 & 1.2 & 1.2 & 86.1 \\
\hline 2.3 & 3 & .9 & .9 & 87.0 \\
\hline 2.31 & 2 & .6 & .6 & 87.7 \\
\hline 2.33 & 2 & .6 & .6 & 88.3 \\
\hline 2.34 & 1 & .3 & .3 & 88.6 \\
\hline 2.36 & 1 & .3 & .3 & 88.9 \\
\hline 2.37 & 2 & .6 & .6 & 89.5 \\
\hline 2.38 & 1 & .3 & .3 & 89.8 \\
\hline 2.39 & 1 & .3 & .3 & 90.1 \\
\hline
\end{tabular}




\begin{tabular}{ccccc}
2.4 & 3 & .9 & .9 & 91.0 \\
2.41 & 1 & .3 & .3 & 91.3 \\
2.42 & 3 & .9 & .9 & 92.2 \\
2.43 & 1 & .3 & .3 & 92.5 \\
2.44 & 2 & .6 & .6 & 93.1 \\
2.49 & 2 & .6 & .6 & 93.7 \\
2.52 & 2 & .6 & .6 & 94.3 \\
2.53 & 1 & .3 & .3 & 94.6 \\
2.54 & 1 & .3 & .3 & 94.9 \\
2.56 & 1 & .3 & .3 & 95.2 \\
2.67 & 1 & .3 & .3 & 95.5 \\
2.69 & 1 & .3 & .3 & 95.8 \\
2.77 & 1 & .3 & .3 & 96.1 \\
2.78 & 1 & .3 & .3 & 96.4 \\
2.84 & 2 & .6 & .6 & 97.0 \\
2.87 & 1 & .3 & .3 & 97.3 \\
2.88 & 1 & .3 & .3 & 97.6 \\
2.89 & 1 & .3 & .3 & 97.9 \\
2.91 & 1 & .3 & .3 & 98.2 \\
2.93 & 1 & .3 & .3 & 98.5 \\
2.96 & 3 & .9 & .9 & 99.4 \\
3.21 & 1 & .3 & .3 & 99.7 \\
3.22 & 1 & .3 & .3 & 100.0 \\
Total & 332 & 100.0 & 100.0 & \\
\hline
\end{tabular}




\section{Appendix B}

Eco-friendly Fashion Related Products Images

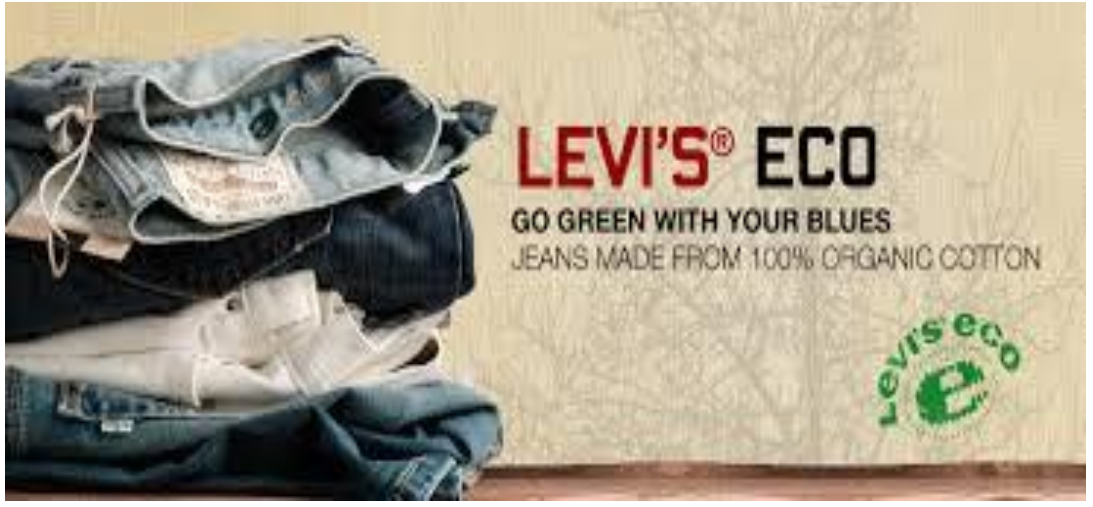

Figure 1. Levi's propose jeans corresponding to environmental requirements throughout the process of manufacture and distribution of product. [Photograph]. (n.d.). Retrieved from https://brandsandco.wordpress.com/

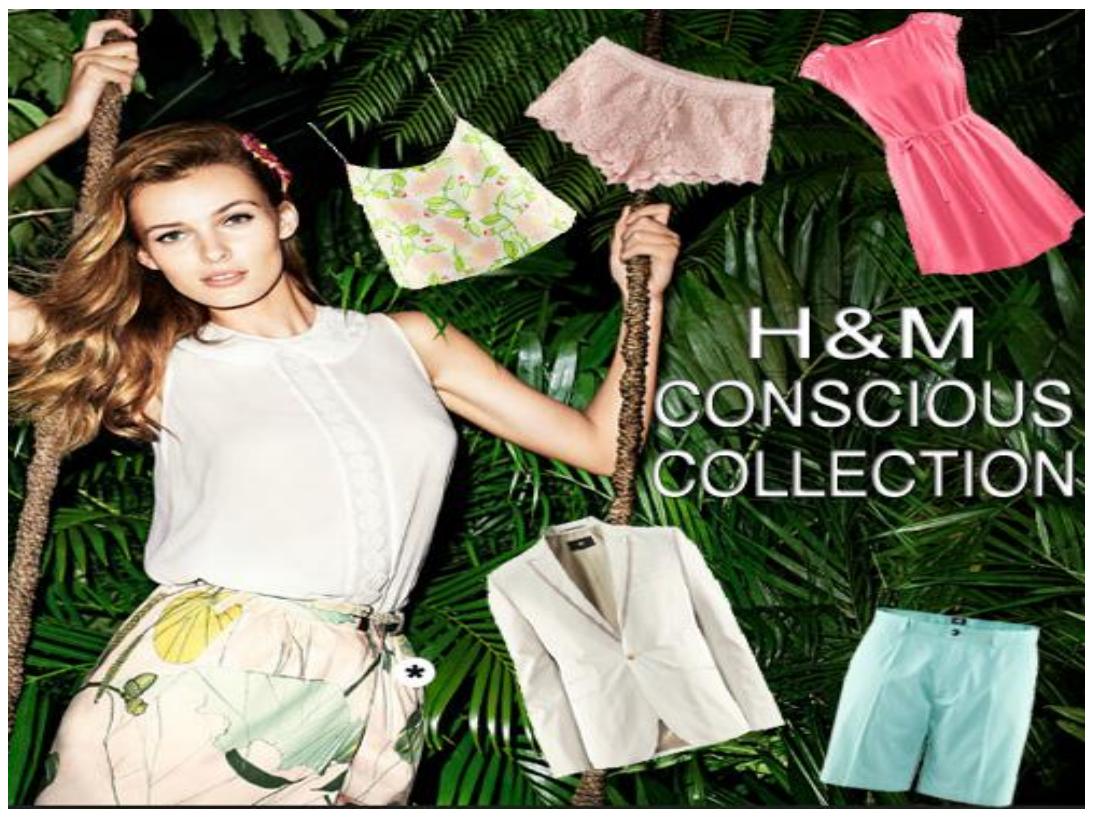

Figure 2. H\&M conscious collection: step toward more sustainable fashion. [Photograph]. (n.d.).

Retrieved from https://hmconsciouswordpressfr.wordpress.com/archives-publicites/ 


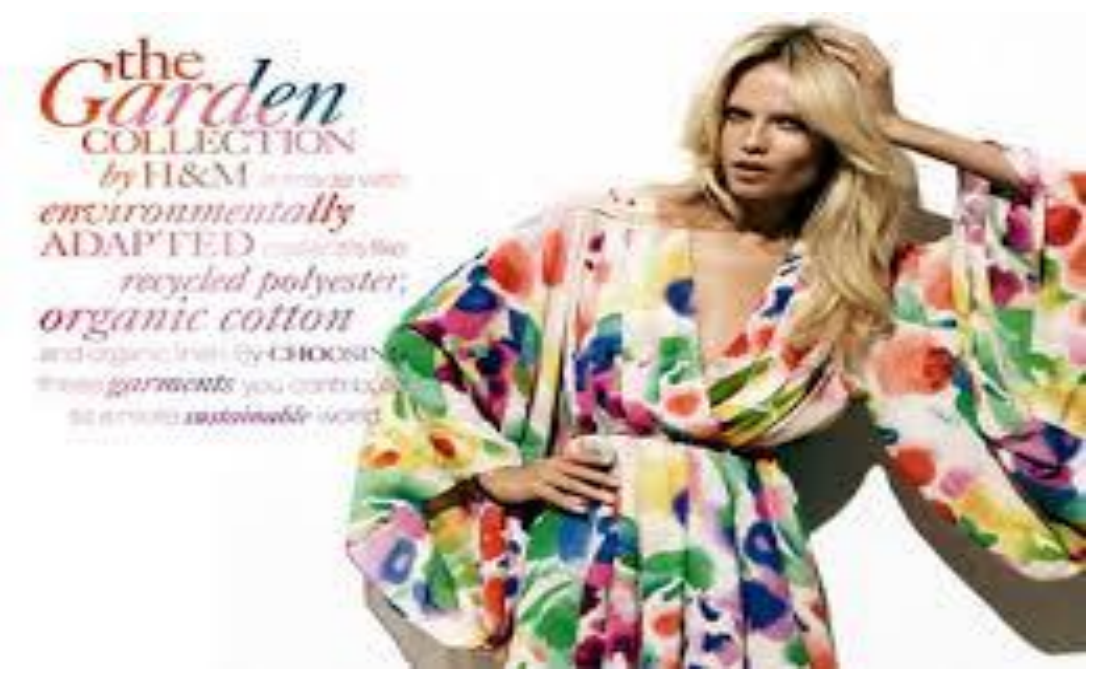

Figure 3. H\&M Garden Collection: everyday ethical fashion. [Photograph]. (n.d.). Retrieved from http://www.fashionchangingtheworld.com/categories/ethical-everyday-fashion

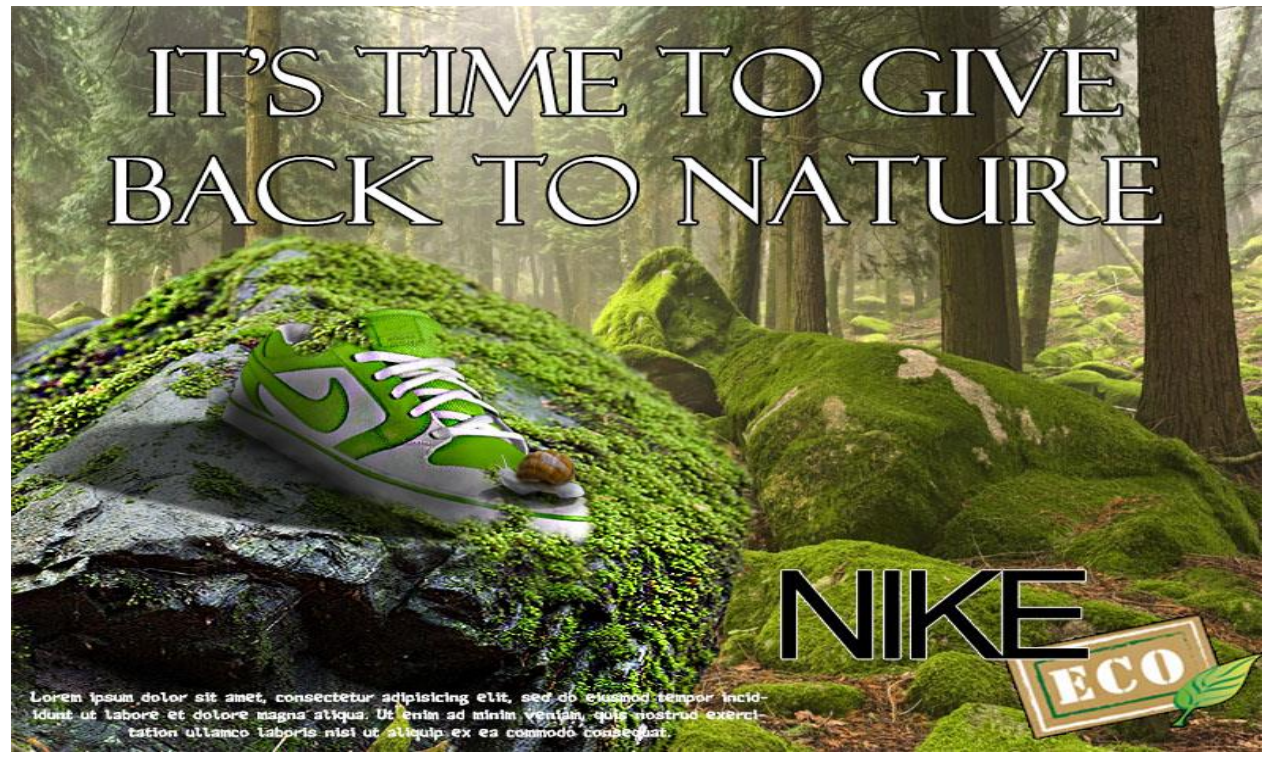

Figure 4. Nike is ambassador of sustainability and the awareness of the subject.

[Photograph].(n.d.). Retrieved from

https://nelsonbusinessandenvironment.wordpress.com/2014/02/ 


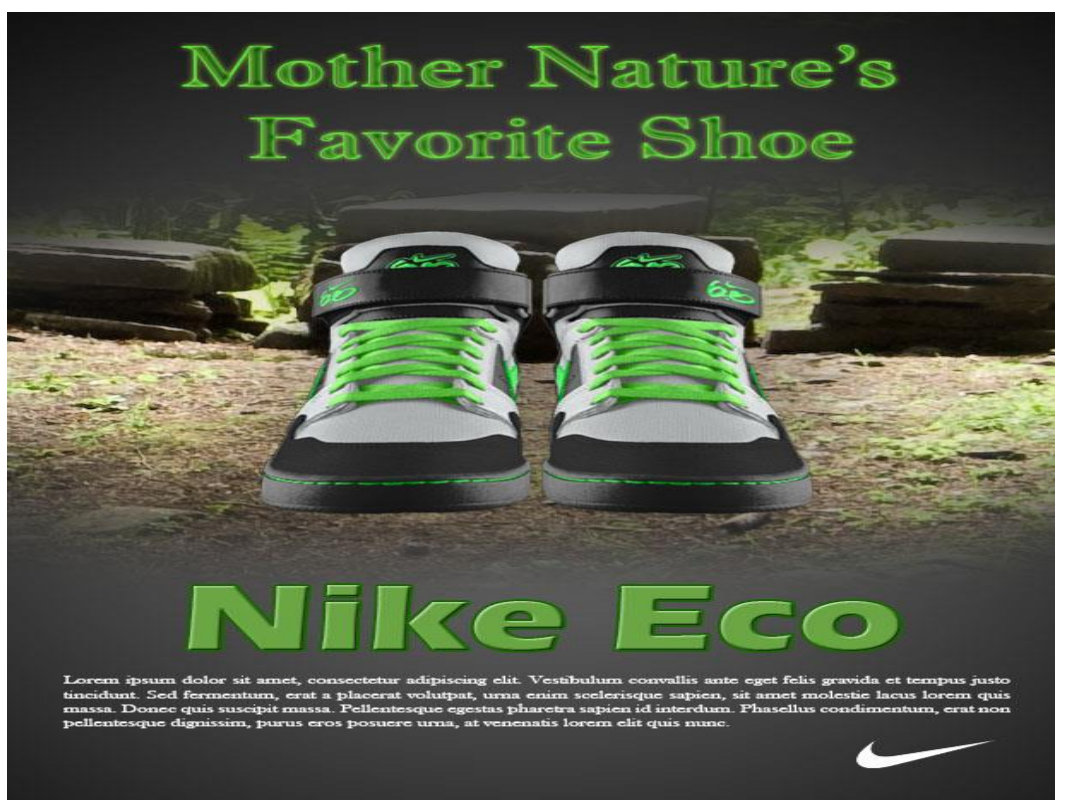

Figure 5. "Nike Eco," a fictional environmental friendly shoe made by Nike. [Photograph]. (n.d.). Retrieved fromhttps://thisiswhereipostmywork.wordpress.com/

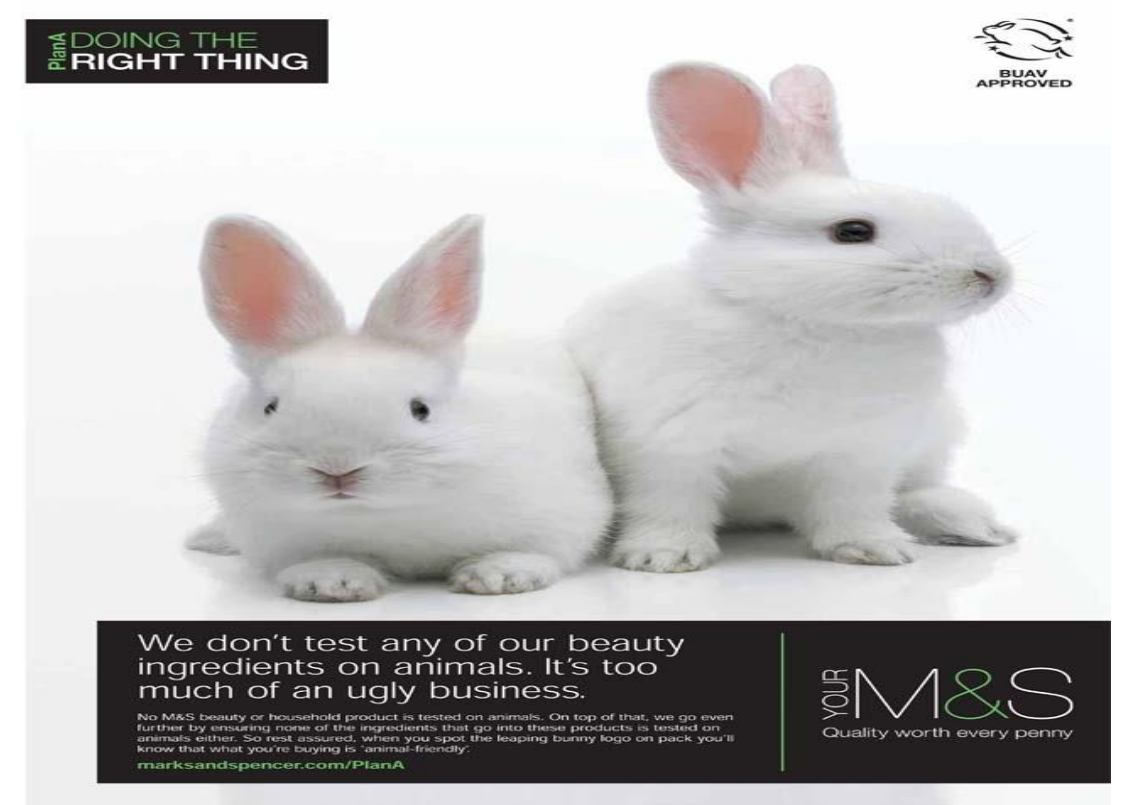

Figure 6. Mark \& Spencer promotes its cruelty-free approval by the internationally recognized BUAV standard. [Photograph]. (n.d.). Retrieved from http://www.fromdusktildawn.org.uk /full_news_page/news_may_june.htm 

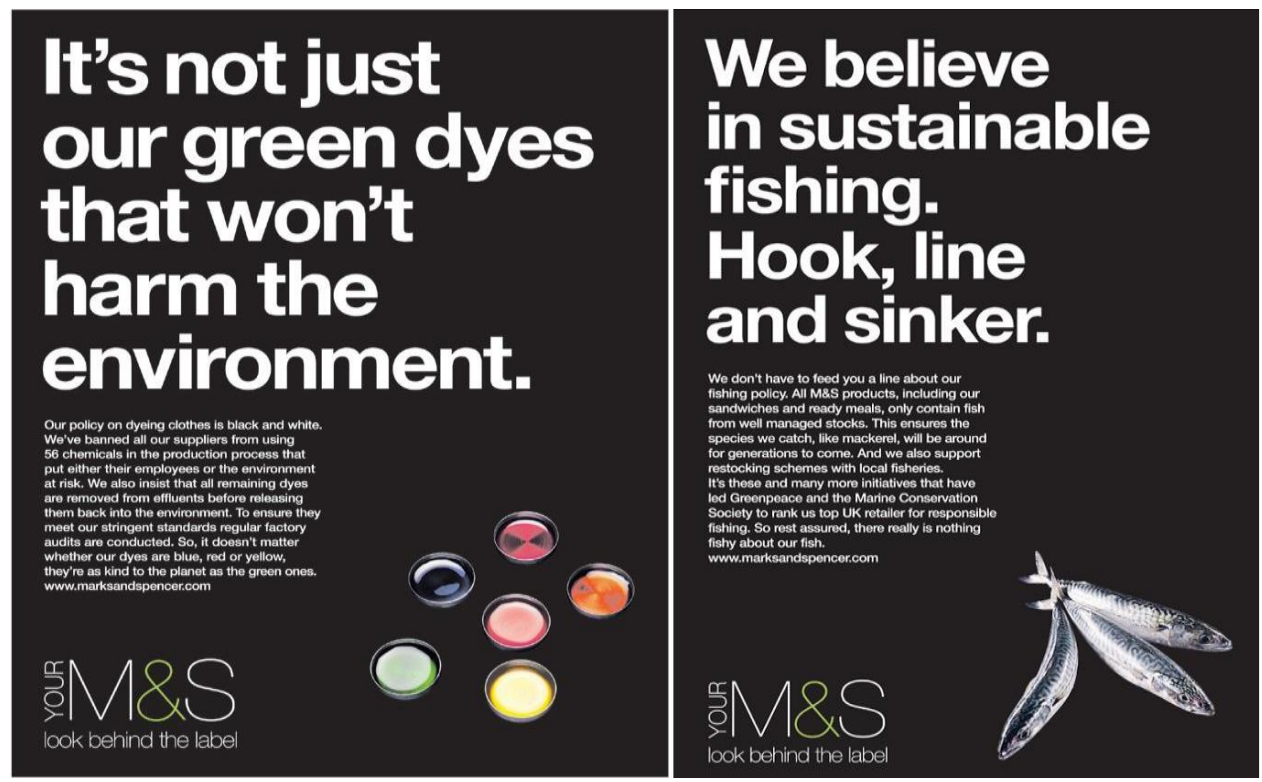

Figure7. Marks \& Spencer, Marketing for Sustainable Consumption. [Photogrph]. (n,d.).

Retrieved fromhttps://www.marketingsociety.com/the-library/2010-marks-spencer-marketingsustainable-consumption

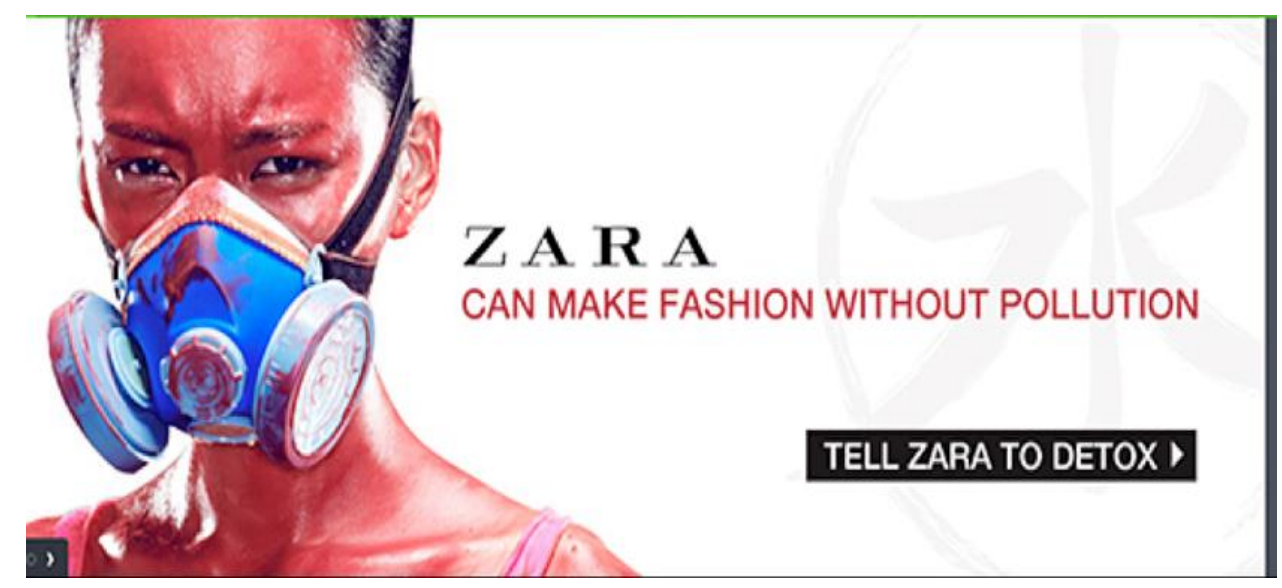

Figure 8. Zara make fashion without pollution. [Photograph]. (n.d.). Retrieved from https://greenadsinchina.wordpress.com/2016/07/11/the-useless-sustainability-eco-fashion 


\title{
Appendix C
}

\author{
Online Survey
}

\section{Consent Form}

\section{INTRODUCTION AND PURPOSE}

My name is Madiha Tahir. I am a Master student Ryerson University working with my faculty supervisor Osmud Rehman in the Department of Fashion Studies. I would like to invite you to take part in my research study for the completion of my Master degree.

\section{WHAT YOU ARE BEING ASKED TO DO}

You are being asked to voluntarily complete this on-line survey. It involves questions about Ecolabelling and Current fashion system, it should take about 10-15 mins to complete. In order for all of your answers to be collected you must go to the end of the survey and click 'submit survey'. This will demonstrate your full consent to participation.

Please note, there is no obligation to participate in this survey, you may withdraw at any time by closing the browser.

\section{POTENTIAL BENEFITS}

There is no direct benefit to you for taking part in this study. It is hoped that the research will help to understand the consumers' behavior toward Eco-labelling in current fashion system.

\section{WHAT IS THE POTENTIAL RISK TO YOU}

If you wish not to answer some questions. You are free to skip any questions you do not wish to answer, or stop participating at any time by closing your browser. If you close your browser before getting to the end of the survey and do not confirm your consent to participate at the end 
of the survey by clicking the 'submit' button your information collected up to that point will not be used.

\section{YOUR IDENTITY WILL BE}

The survey is anonymous and as such will not be collecting information that will easily identify you, like your name or other unique identifiers. Although your Internet Protocol (IP) address can be tracked through the survey platform, the researcher/s will not be collecting this information. Your IP address may be observed only to ensure that one individual is not completing the survey multiple times.

\section{HOW YOUR INFORMATION WILL BE PROTECTED AND STORED}

This survey uses Survey Monkey which is a United States of America (USA) company. To further protect your information, data stored by the researcher will be password protected and/or encrypted. Your individual responses (i.e. raw data) will not be shared with anyone outside of the research team. The data with no personal identifiers, collected from this study will be maintained on password protected computer database. In addition, the data will be electronically archived after completion of the study and store for four years and then erased.

Consequently, USA authorities under the provisions of the Patriot Act may access the survey data. If you would rather participate with an email or paper-based survey please contact the researchers. Please note email or paper-based surveys may allow your identity to be known to the researcher/s but if you select this option your information will be kept confidential.

\section{YOUR RIGHTS AS A RESEARCH PARTICIPANT}

Participation in research is completely voluntary and you can withdraw your consent at any point up to clicking the submit button at the end of the survey. However, because the survey is 
anonymous, once you click the submit button at the end of the survey the researchers will not be able to determine which survey answers belong to you so your information cannot be withdrawn after that point.

Please note, that by clicking submit at the end of the study you are providing your consent for participation. By consenting to participate you are not waiving any of your legal rights as a research participant. Please proceed if your age is 18 or above.

\section{QUESTIONS}

If you have any questions about this research, please feel free to contact the researcher/s

Madiha Tahir (madiha.tahir@ryerson.ca.)

Osmud Rahman (orahman@ ryerson.ca)

If you have any questions about your rights or treatment as a research participant in this study, please contact the Ryerson University Research Ethics Board at rebchair@ ryerson.ca (416) 9795042.

Please note if you wish, you may request the copy of the findings by contacting the researcher through email. If you wish to forward this link please feel free to do so.

Please print a copy of this page for your future reference.

Q. Do you agree to take part in this survey?

- Yes

- No 
Survey Questions

\section{Section 1: Eco-labelling}

NOTE: The term "Eco-friendly", for use of this survey, is defined as: goods and services considered to inflict minimal or no harm on the environment. Please circle one answer

Please select the best option.

1. I believe that environmental information on product label is important

Strongly Agree

Agree

Neutral

Disagree

Strongly

Disagree

2. I generally believe in the environmental information on product label

Strongly Agree

Agree

Neutral

Disagree

Strongly

Disagree

3. I understand the concept of environmental certification

Strongly Agree

Agree

Neutral

Disagree

Strongly

Disagree

4. I believe there is a lot that individuals can do to improve the environment

Strongly Agree

Agree

Neutral

Disagree

Strongly

Disagree

5. I believe there is a lot that corporations can do to improve the environment 
Strongly Agree

Agree

Neutral

Disagree

Strongly

Disagree

6. I believe that there is a need for environmental certification of the fashion related products

Strongly Agree

Agree

Neutral

Disagree

Strongly

Disagree

7. I believe environmental certification can be helpful for buyers

Strongly Agree

Agree

Neutral

Disagree

Strongly

Disagree

8. If available, I would seek out environmentally certified clothes

Strongly Agree

Agree

Neutral

Disagree

Strongly

Disagree

9. Whenever possible, I buy products which I consider environmentally safe

Strongly Agree

Agree

Neutral

Disagree

Strongly

Disagree

10. I would pay more for environmentally friendly products

Strongly Agree

Agree

Neutral

Disagree

Strongly

Disagree

11. I would pay a premium for certified clothing

Strongly Agree

Agree

Neutral

Disagree

Strongly

Disagree

12. I am ready to pay more for certified eco-friendly products 
Strongly Agree

Agree

Neutral

Disagree

Strongly

Disagree

13. I would be willing to reduce my consumption to help protect the environment

Strongly Agree

Agree

Neutral

Disagree

Strongly

Disagree

14. Protecting the natural environment increases my quality of life

Strongly Agree

Agree

Neutral

Disagree

Strongly

Disagree

15. When I have the choice between two equal clothing items, I purchase the one less harmful to others and the environment

Strongly Agree

Agree

Neutral

Disagree

Strongly

Disagree

16. I would avoid buying clothing items if it had potentially harmful environmental effects

Strongly Agree

Agree

Neutral

Disagree

Strongly

Disagree

17. Supporting environmental protection makes me more committed to the environment

Strongly Agree

Agree

Neutral

Disagree

Strongly

Disagree

18. I would rather spend my money on eco-friendly clothes more than anything else

Strongly Agree

Agree

Neutral

Disagree

Strongly

Disagree 
19. I believe that the price of eco-friendly clothing is usually more on average

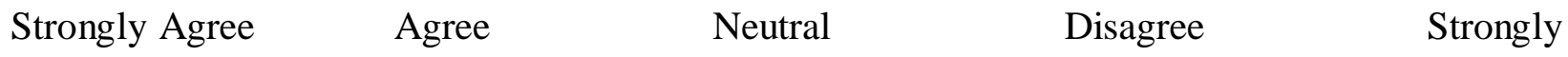

Disagree

20. I prefer to purchase Eco-clothing even if it is somewhat more expensive

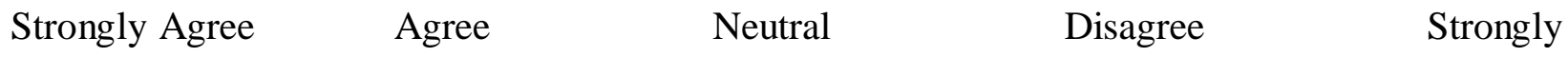

Disagree

21. I believe a clothing brand with certified eco-friendly label is a socially acceptable brand to purchase.

$\begin{array}{llll}\text { Strongly Agree } & \text { Agree } & \text { Neutral } & \text { Disagree }\end{array}$

Disagree

22. I would rather stick with a well known conventional clothing brand than try Eco-friendly brand

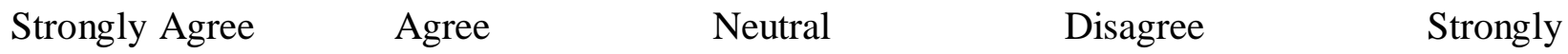

Disagree

23. If I like a brand, I rarely switch from it just to try something different

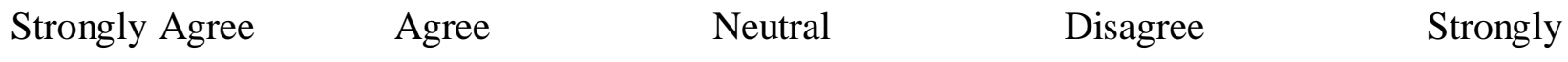

Disagree

24. It makes no difference to me if Eco-friendly clothing are not branded

$\begin{array}{llll}\text { Strongly Agree } & \text { Agree } & \text { Neutral } & \text { Disagree }\end{array}$

Disagree

25. I believe that Eco-friendly clothing such as organic cotton etc. is more fashionable than conventional clothing 
Strongly Agree

Agree

Neutral

Disagree

Strongly

Disagree

26. I believe that the quality of Eco-friendly clothing is usually higher than other clothing items

Strongly Agree

Agree

Neutral

Disagree

Strongly

Disagree

27. I believe that the country can have a positive influence on the environment

Strongly Agree

Agree

Neutral

Disagree

Strongly

Disagree

28. Supporting environmental protection makes me more socially responsible

Strongly Agree

Agree

Neutral

Disagree

Strongly

Disagree

29. I am satisfied with purchasing Eco-friendly clothing and hence would buy

Strongly Agree

Agree

Neutral

Disagree

Strongly

Disagree

30. Do you know about any of these popular textile Eco-labels?

- Fair trade

- Care \& Fair-Siege

- Global Organic Textile Standard

- Fair Wear Foundation

- Clean Clothes Campaign 
- Oeko-Tex Standard 100

\section{Section 2: Consumer behavior}

31. How important the following factors can affect your purchasing decision of clothing?

\begin{tabular}{|c|c|c|c|c|c|}
\hline & $\begin{array}{l}\text { Very } \\
\text { unimportant }\end{array}$ & Unimportant & Neutral & Important & Very important \\
\hline Garment fi & & & & & \\
\hline Quality & & & & & \\
\hline Comfort & & & & & \\
\hline Color & & & & & \\
\hline Style & & & & & \\
\hline Fiber/ Mate & & & & & \\
\hline Brand & & & & & \\
\hline Price & & & & & \\
\hline Garment lif & & & & & \\
\hline Country of & & & & & \\
\hline Durability & & & & & \\
\hline
\end{tabular}




\begin{tabular}{|l|l|l|l|l|}
\hline Certified Eco- & & \\
Friendly Label & & & \\
\hline Certified Ethical & & & \\
Label & & & \\
(sweatshop-free & & & \\
products)
\end{tabular}

\section{Section 3: Fashion trend}

32. In general, I am the last in my circle of friends to know the names of the latest designers and fashion trends

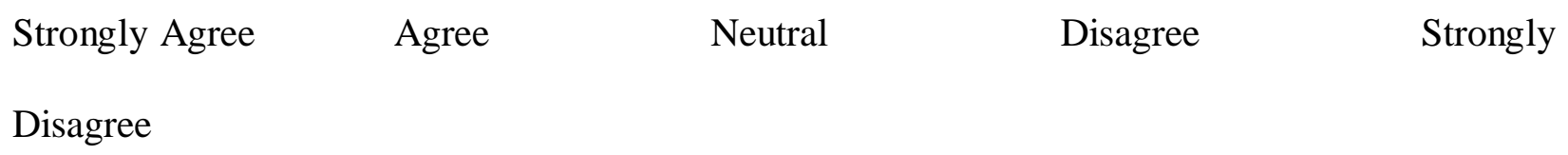

33. Compare to my friends, I do little shopping for new fashion styles

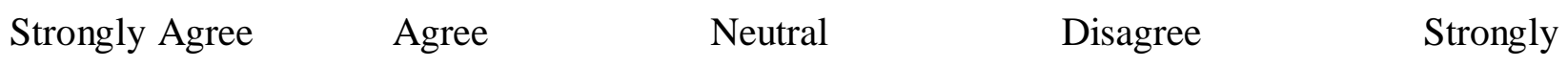

Disagree

34.In general, I am the last among my circle of friends to purchase new fashion styles

$\begin{array}{llll}\text { Strongly Agree } & \text { Agree } & \text { Neutral } & \text { Disagree }\end{array}$

Disagree

35. I know more about new fashion styles before other people do

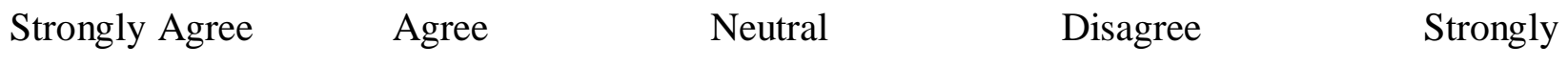

Disagree 
36. If I heard that new fashion styles or look was available through a local boutique or department store I would be interested enough to buy it

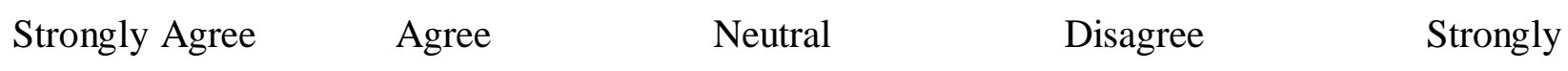

Disagree

37. I will consider buying new fashion styles even if I haven't heard of it yet

Strongly Agree

Agree

Neutral

Disagree

Strongly

Disagree

Section 4 : Ethics

38. How important the following factors can affect your purchasing decision of clothing?

\begin{tabular}{|l|l|l|l|l|l|}
\hline & Very Important & Important & Neutral & Unimportant & Very \\
\hline Less Water use & & & & Unimportant \\
\hline Air quality & & & & \\
\hline Less Energy use & & & & \\
\hline Worker safety & & & & \\
\hline Fair wages & & & & \\
\hline No child labor & & & & \\
\hline No animal skin use & & & \\
\hline recycling & & & \\
\hline
\end{tabular}


39. How much money do you spend on clothing per year?

- Less than $5 \%$ of my income

- $\quad 5-10 \%$ of my income

- $\quad 10-15 \%$ of my income

- $15-20 \%$ of my income

- $\quad 20-25 \%$ of my income

- $25-30 \%$ of my income

- More than $30 \%$ of my income

\section{Section 5 : Demographics}

40. What is your employment status?

- Student

- Full-time Employee

- Part-time Employee

- Self-Employed

- Unemployed

- $\quad$ Other -----------

41. Gender:

- Male

- Female 
- Other

42. To which income bracket do you belong to (as a family)

- 0 - US $\$ 44,000$

- US\$45,000 - US\$59,000

- US\$60,000 - US\$65,000

- US\$66,000 - US\$75,000

- US\$76,000 - US\$85,000

- US\$86,000 - US\$95,000

- More than US\$95,000

43. What is your age?

- $18-24$

- $25-34$

- $35-44$

- $45-54$

- $55-64$

- $65-74$

- 75 or older

44. What is the highest level of education you have completed?

- Did not attend School 
- Graduate from School

- Graduate from College

- Master

- Doctorate

45. What is your current relationship status

- Married

- Widow

- Divorced

- Separated

- Single

46. In which country do you live? 


\section{$\begin{array}{ll}\text { Ryerson } & \text { Research } \\ \text { Ethics Board }\end{array}$}

To: Madiha Tahir

Fashion

Re: REB 2017-207: Fashion and Ethical responsibility

Date: July 7, 2017

\section{Dear Madiha Tahir,}

The review of your protocol REB File REB 2017-207 is now complete. The project has been approved for a one year period. Please note that before proceeding with your project, compliance with other required University approvals/certifications, institutional requirements, or governmental authorizations may be required.

This approval may be extended after one year upon request. Please be advised that if the project is not renewed, approval will expire and no more research involving humans may take place. If this is a funded project, access to research funds may also be affected.

Please note that REB approval policies require that you adhere strictly to the protocol as last reviewed by the REB and that any modifications must be approved by the Board before they can be implemented. Adverse or unexpected events must be reported to the REB as soon as possible with an indication from the Principal Investigator as to how, in the view of the Principal Investigator, these events affect the continuation of the protocol.

Finally, if research subjects are in the care of a health facility, at a school, or other institution or community organization, it is the responsibility of the Principal Investigator to ensure that the ethical guidelines and approvals of those facilities or institutions are obtained and filed with the REB prior to the initiation of any research.

Please quote your REB file number (REB 2017-207) on future correspondence.

Congratulations and best of luck in conducting your research.

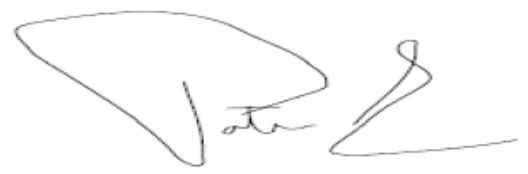

Dr. Patrizia Albanese, $\mathrm{PhD}$

Chair, Ryerson University Research Ethics Board

The Following protocol attachments have been reviewed and approved. 
- Literature Review-4th June.docx (submitted on: 05 Jun 2017)

- Methodology-4thjune.docx (submitted on: 05 Jun 2017)

- consent-6th July.docx (submitted on: 06 Jul 2017)

- screen shots-6th july.docx (submitted on: 06 Jul 2017)

- Recruitment notice-6th July.docx (submitted on: 06 Jul 2017)

- Responses.docx (submitted on: 07 Jul 2017)

If any changes are made to the attached document throughout the course of the research, an amendment MUST be submitted to, and subsequently approved by the REB. 


\section{References}

Anderson B (ed.)., 1990. Eclogue: the Environmental Catalogue and Consumer's Guide for a Safe Earth. Prentice-Hall: New York.

Aspers, P. \& L. Skov., 2006. Encounters in the global fashion business." Current Sociology, 54: 745-63.

Aspers, P., 2008. Labelling fashion markets. International Journal of Consumer Studies, 32(6): 633-638.

Beard, N. D. 2008. The branding of ethical fashion and the consumer: A luxury niche or massmarket reality? Fashion Theory, 12(4): 447-468.

Bernard, Y., Bertrandias, L. \& Elgaaied-Gambier, L., 2015. Shoppers' grocery choices in the presence of generalized eco-labelling. International Journal of Retail \& Distribution Management, 43(4/5): 448-468.

Black, S. 2008. Eco-chic: The fashion paradox. London, UK: Black Dog.

Blend, J.R., van Ravenswaay, O.E., 1999. Measuring consumer demand for ecolabeled apples. American Journal of Agricultural Economics, 81(5): 1072-1077.

Borin, N., Cerf, D. C., \& Krishnan, R., 2011. Consumer effects of environmental impact in product labeling. Journal of Consumer Marketing, 28(1): 76-86.

Borin, N., Cerf, D. C., \& Krishnan, R., 2011. Consumer effects of environmental impact in product labeling. Journal of Consumer Marketing, 28(1):76-86.

Bradu, C., Orquin, J. L., \& Thøgersen, J., 2013. The mediated influence of a traceability label on consumer's willingness to buy the labelled product. Journal of Business Ethics, 116.

Bryman, A. \& Bell, E., 2015. Business research methods. Oxford University Press, USA. 
Callen-Marchione, K.S. and Ownbey, S.F., 2008. Associations of unethical consumer behavior and social attitudes. Journal of Fashion Marketing and Management: An International Journal, 12(3): pp.365-383.

Carey, L., Shaw, D. \& Shui, E., 2008. "The impact of ethical concerns on family consumer decision-making”, International Journal of Consumer Studies, 32(5): pp. 553-60.

Carrero, I \& Valor, C., 2012. "CSR-labelled products in retailers' assortment: A comparative study of British and Spanish retailers", International Journal Of Retail \& Distribution Management, 40(8): pp. 629-652.

Carrigan, M. \& Attalla, A., 2001. "The myth of the ethical consumer - do ethics matter in purchase behavior?", Journal of Consumer Marketing, 18(7): pp. 560-78.

Chan, R., Wong, Y. and Leung, T., 2008, “Applying ethical concepts to the study of 'green' consumer behavior: an analysis of Chinese consumers' intentions to bring their own shopping bags", Journal of Business Ethics, 79(4): pp. 469-81.

Chan, T. Y., \& Wong, C. W. Y., 2012. The consumption side of sustainable fashion supply chain: Understanding fashion consumer eco-fashion consumption decision. Journal of Fashion Marketing and Management, 16(2): 193-215.

Chen, T. B., \& Chai, L. T., 2010. Attitude towards the environment and green products: consumers' perspective. Management science and engineering, 4(2): 27.

Cherian, J., \& Jacob, J., 2012. Green marketing: A study of consumers' attitude towards environment friendly products. Asian Social Science, 8(12): 117-126.

Creyer, E.H., 1997, "The influence of firm behavior on purchase intention: do consumers really care about business ethics?", Journal of Consumer Marketing, 14 (6): pp. 421-32. 
D'Souza, C., 2004. Ecolabel programmes: A stakeholder (consumer) perspective. Corporate Communications: An International Journal, 9(3): 179-188.

D’Souza, C., Taghian, M. \& Lamb, P., 2006b, “An empirical study on the influence of environmental labels on consumers", Corporate Communications: An International Journal, 11(2): 162-173.

D’Souza, C., Taghian, M., Lamp, P., \& Peretiatkos, R., 2006a. Green products and corporate strategy: an empirical investigation. Society and Business Review, 1(2): 144-157.

De Brito, M. P., Carbone, V. \& Blanquart, C. M., 2008. "Towards a sustainable fashion retail supply chain in Europe: Organisation and performance." International Journal of Production Economics 114(2): 534-553.

Dickson M. A., 2001. Utility of no sweat labels for apparel consumers: Profiling label users and predicting their purchases. The Journal of Consumer Affairs, 35(1): 96-119.

Doyle, J., 1992. Hold the Applause: A Case Study of Corporate Environmentalism. The Ecologist, 22(3), 84-90.

Dr Julian Allwood. "Well Dressed?" University of Cambridge, 1 apr. 2007, www.cam.ac.uk/research/news/well-dressed.

Emberley, V., 1998. "Venus and Furs: The Cultural Politics of Fur.” I. B. Tauris \& Co.

Esty, D. \& Winston, A., 2009. Green to gold: How smart companies use environmental strategy to innovate, create value, and build competitive advantage. John Wiley \& Sons.

Ethical Fashion Forum [EFF]. 2014. "Our mission." Ethical Fashion Forum. http://www.ethicalfashionforum.com/about-eff/our-mission (accessed 15 June, 2017). 
Fletcher, K., 2008. Sustainable fashion and textiles: design journeys, Earthscan. London, Sterling.

Fliess, B., Lee, H.-Y., Dubreuil, O. L., \& Agatiello, O. R., 2007. CSR and trade: Informing consumers about social and environmental conditions of globalized production (OECD Trade Policy Working Paper No. 47).

Gallastegui, I. G., 2002. The use of eco-labels: A review of the literature. European Environment, 12(6): 316-331. doi:10.1002/eet.304

Ghauri \& Cateora 2005, International Marketing, 2nd edition, UK, McGraw Hill

Göçer, A., \& Oflac, B. S., 2017. Understanding young consumers’ tendencies regarding ecolabelled products. Asia Pacific Journal of Marketing and Logistics, 29(1): 80-97. doi:10.1108/APJML-03-2016-0036

Goswami, P., 2008. Is the urban Indian consumer ready for clothing with eco-labels?. International journal of consumer studies, 32(5): 438-446.

Grankvist, G., Dahlstrand, U., \& Biel, A., 2004. The impact of environmental labelling on consumer preference: Negative vs. positive labels. Journal of Consumer Policy, 27(2): 213-230. doi:10.1023/B:COPO.0000028167.54739.94

Gulbrandsen, L. H., 2006. Creating markets for eco-labelling: Are consumers insignificant? International Journal of Consumer Studies, 30(5): 477-489.

Haug, A., \& Busch, J., 2016. Towards an ethical fashion framework. Fashion Theory, 20(3): 317-339. doi:10.1080/1362704X.2015.1082295

Hawken, P., 1993. The ecology of commerce: A declaration of sustainability. London: Phoenix. 
Hethorn, J. \& Ulasewicz, C., 2008. Sustainable fashion: Why now. A conversation exploring issues, practices, and possibilities. A \& C Black Publishers Ltd, Newyork, USA.

Hoek, J., Roling, N. \& Holdsworth, D., 2013. "Ethical claims and labelling: An analysis of consumers' beliefs and choice behaviors”, Journal of Marketing Management, 29(7/8): pp. $772-792$.

Horne, R. E., 2009. Limits to labels: The role of eco-labels in the assessment of product sustainability and routes to sustainable consumption. International Journal of Consumer Studies, 33(2): 175-182.

Jägel, T., Keeling, K., Reppel, A., \& Gruber, T., 2012. Individual values and motivational complexities in ethical clothing consumption: A means-end approach. Journal of Marketing Management, 28(3/4): 373-396.

Jana, R., 2006. Green threads for the eco chic. Business Week Online, p14

Joergens, C., 2006. "Ethical fashion: myth or future trend?", Journal of Fashion Marketing and Management, 10(3): pp. 360-71.

Johansson, B., 1995. Quantitative or qualitative research-or a combination. A matter of decisionmaking from theories of research methodology.

Jordan, A., Wurzel, R., Zito A., \& Brückner, L., 2004. Consumer responsibility-taking and national eco-labelling schemes in Europe. In M. Micheletti, A. Follesdal, \& D. Stolle (Eds.), Politics, products and markets: Exploring political consumerism (pp. 161-180). Somerset, NJ: Transaction. 
Jordan, A., Wurzel, R., Zito, A. R., \& Brückner, L., 2003. European Governance and the Transfer of 'new' environmental policy instruments (NEPIs) in the European Union. Public Administration, 81(3): 555-574.

Joy, A., Sherry, J. F., Jr., Venkatesh, A., Wang, J., \& Chan, R., 2012. Fast fashion, sustainability, and the ethical appeal of luxury brands. Fashion Theory, 16(3): 273-295.

Kelvin Stiles., 2016. "Paper Surveys vs Online Surveys - Which One's Better?” Free Online Survey Software,

Kempen, L., Muradian, R., Sandoval, C. \& Castaneda, J., 2009. “Too poor to be green consumers? A field experiment on revealed preferences for firewood in rural Guatemala", Ecological Economics, 68(7): 2160-2167.

Kent, R., 2007. Marketing Research: approaches, methods and applications in Europe. London: Thomson Learning.

Koszewska, M., 2011. Social and eco-labelling of textile and clothing goods as means of communication and product differentiation. Fibres \& Textiles in Eastern Europe, 19(4): 20-26.

Koszewska, M., 2011. Social and eco-labelling of textile and clothing goods as means of communication and product differentiation. Fibres \& Textiles in Eastern Europe, 19(4): p.87.

Kotler P., Keller K., Brady M., Goodman M., and Hansen T., 2009. Marketing Management. 13th edition, London: Pearson. 
Leire, C., \& Thidell, Å., 2005. Product-related environmental information to guide purchases. A review and analysis of research on perceptions, understanding and use among Nordic consumers. Journal of Cleaner Production, 13(10/11): 1061-1070.

Liu, Q., Yan, Z., \& Zhou, J., 2017. Consumer choices and motives for eco-labeled products in China: An empirical analysis based on the choice experiment. Sustainability, 9(3).

Lundblad, L., \& Davies, I. A., 2015. The values and motivations behind sustainable fashion consumption. Journal of Consumer Behavior, 15(2): 149-162.

Mainieri, T., Barnett, E. G., Valdero, T. R., Unipan, J. B., \& Oskamp, S., 1997. Green buying: The influence of environmental concern on consumer behavior. The Journal of social psychology, 137(2): 189-204.

Mattoo, A. \& Singh, H.V., 1994. Eco-Labelling: Policy Considerations. Kyklos, 47(1): pp.53-65.

Mohr, L. A., Webb, D. J., \& Harris, K. E., 2001. Do consumers expect companies to be socially responsible? The impact of corporate social responsibility on buying behavior. Journal of Consumer Affairs, 35(1): 45-72.

Moisander, Johanna \& S. Personen., 2002. "Narratives of Sustainable Ways of Living: Constructing the Self and Others as a Green Consumer." Management Decision 40(4): $329-42$.

Moon, W., Florkowski, W. J., Brückner, B., \& Schonhof, I., 2002. Willingness to pay for environmental practices: implications for eco-labeling. Land Economics, 78(1): 88-102.

Morris J., 1997. Green Goods?: Consumers, Product Labels and The Environment, Studies on the Environment. IEA. 
Muller, K. E., \& Fetterman, B. A., 2002. Regression and ANOVA: an integrated approach using SAS software. SAS Institute.

Nicholls, A. \& Lee, N., 2006. "Purchase decision-making in fair trade and the ethical purchase 'gap': 'is there a fair trade twix?'”, Journal of Strategic Marketing, 14(4): pp. 369-86.

Niinimäki, K., 2009. Consumer values and eco-fashion in the future. In FFRC eBook (pp. 125134). Retrieved from http://orgprints.org/16410/

Nimon, W., Beghin, J., 1999. Are eco-labels valuable? Evidence from the apparel industry. American Journal of Agricultural Economics 81(4): 801-811.

Ormrod, J. E., \& Leedy, P. D., 2005. Practical research: Planning and design. New Jersey, Pearson Merill Prentice hall.

Paulins, V.A. and Hillery, J.L., 2009. Ethics in the Fashion Industry, Fairchild Books, New York, NY.

Porter, M. E., \& Van der Linde, C., 1995. Green and competitive: ending the stalemate. Harvard business review, 73(5): 120-134.

Proto, Maria, Ornella Malandrino, \& Stefania Supino., 2007. "Eco-labels: a sustainability performance in benchmarking?." Management of Environmental Quality: An International Journal 18(6): 669-683.

Ramlogan, R., 1997. Environment and human health: a threat to all. Environmental Management and Health, 8(2): 51-66. 
Raziuddin Taufique, K. M., Siwar, C., Talib, B., Hasan Sarah, F., \& Chamhuri, N., 2014. Synthesis of constructs for modeling consumers' understanding and perception of ecolabels. Sustainability, 6(4): 2176-2200. doi:10.3390/su6042176

Rex, E. Baumann, H., 2007. "Beyond ecolabels: What green marketing can learn from conventional marketing”, Journal of cleaner production, 15, pp. 567-576.

Ross, John K. 111, Larry Patterson, \& Mary Ann Stutts., 1992. Consumer Perceptions of Organiza- tions That Use Cause-Related Marketing. Journul cfthe Acudemy ofMarketing Science, 20(I): 93-97.

Rossi, P.H., Wright, J.D., \& Anderson, A.B., 1983. Handbook of Survey Research. New York: Academic Press, Inc.

Sammer, K. and Wüstenhagen, R., 2006. "The influence of eco-labelling on consumer behavior results of a discrete choice analysis for washing machines", Business Strategy and the Environment, 15(3): pp. 185-199

Saunders, J., 2010. Are There Too Many Eco-Labels and Green Ratings. Retrieved on April, 19, 2012.

Saunders, M., Lewis, P., \& Thornhill, A., 2000. Research Methods for Business Students. 2nd Edition. Harlow: Pearson Education Limited.

Scherreik, S., 2000. A conscience doesn't have to make you poor. Business Week, pp. 204-208.

Schoeni, R. F., Stafford, F., McGonagle, K. A., \& Andreski, P., 2013. Response rates in national panel surveys. The ANNALS of the American Academy of Political and Social Science, 645(1): 60-87. 
Seiberling, I., 2007. Eco-friendly fabrics don't come cheap: Canadian designer appeals to suppliers for sustainable materials, despite the cost. Edmonton Journal.

Shaw, Deirdre, \& D. Tomolillo., 2004. "Undressing the ethical issues in fashion: a consumer perspective." International retail marketing: A case study approach, pp 141-152.

Shen, B., Wang, Y., Lo, C. K. Y., \& Shum, M., 2012. The impact of ethical fashion on consumer purchase behavior. Journal of Fashion Marketing and Management: An International Journal, 16(2): 234-245.

Sønderskov, K. M., \& Daugbjerg, C., 2011. The state and consumer confidence in eco-labeling: Organic labeling in Denmark, Sweden, the United Kingdom and the United States. Agriculture and Human Values, 28(4): 507-517.

Stone, E., 2007. In Fashion: Fun! Fame! Fortune! New York, NY: Fairchild Books.

Stone, E., 2008. The dynamics of fashion (3rd ed.). New York, NY: Fairchild Books.

Szeniawska K., Fairtrade., 2007. - co się dzieje ze sprawiedliwą modą ,Pomagamy’, nr 26.

Tallontire, A., Rentsendorj, E., \& Blowfield, M., 2001. Ethical consumers and ethical trade: A review of current literature (NRI Policy Series 12).

Teisl M. F., Roe B., Hicks R. L., 2002, Can Eco-label tune a market? Evidence from DolphinSafe Labeling. Journal of Environmental Economics and Management, 43: pp. 339-359

TemaNord., 2001. Evaluation of the environmental effects of the Swan eco-label—Final analysis. Copenhagen, Denmark: Nordic Council of Ministers.

TemaNord., 2001b. Food Labeling Nordic Consumers Proposal for improvement: A pan-Nordic survey of consumer behavior and attitudes towards food labeling. Copenhagen: Nordic Council of Ministers. 
Thidell, Å, 2009. Influences, effects and changes from interventions by eco-labelling schemesWhat a Swan can do?. International Institute for Industrial Environmental Economics, Lund University.

Thøgersen, J., 2000. Psychological determinants of paying attention to eco-labels in purchase decisions: Model development and multinational validation. Journal of Consumer Policy, 23(3): 285-313.

Thøgersen, J., Haugaard, P., \& Olesen, A., 2010. "Understanding consumer responses to ecolabels”, European Journal of Marketing, 44(11/12): pp. 1787 - 1810.

Thøgersen, J., Jørgensen, A.-K. and Sandager, S., 2012, “Consumer decision making regarding a “green” everyday product” Psychology and Marketing, 29(4): pp. 187- 197.

Trosset, M. W., 2006. An Introduction to Statistical Inference and Its Applications. Williamsburg, VA: Unpublished.

Vanclay, J. K., Shortiss, J., Aulsebrook, S., Gillespie, A. M., Howell, B. C., Johanni, R., \& Yates, J., 2011. Customer response to carbon labelling of groceries. Journal of Consumer Policy, 34(1): 153-160. doi:10.1007/s10603-010-9140-7

Vandermerwe, S., \& Michael, D. O., 1990. Customers Drive Corporations Green. Long Range Planning, 23(6): 10-16.

Varadarajan, P. Rajan \& Anil Menon., 1988. Caus-eRelated Marketing: A Coalignment of Market- ing Strategy and Corporate Philanthropy. Journul c\$Murketing, 52 :58-74. 
Vitalis, V., 2002. Private voluntary eco-labels: Trade distorting, discriminatory and environmentally disappointing. Background paper for the round table on sustainable development, OECD, Paris, 6th December.

Vlosky, R.P., Ozanne, L.K. \& Fontenot, R.J., 1999. A conceptual model of US consumer willingness-to-pay for environmentally certified wood products. Journal of Consumer Marketing, 16: 122-140.

Webb, Deborah J. \& Lois A. Mohr., 1998. A Typology of Consumer Responses to CauseRelated Marketing: From Skeptics to Socially Concerned. Journul of public Policy undhturketing, 17(2): 226-238.

Weiss, C., Trevenen, A., \& White, T., 2014. The branding of sustainable fashion. Fashion, Style \& Popular Culture, 1(2): 231-258.

Wilson, E., 2003. Adorned in Dreams, Fashion and Modernity. London, UK: Tauris and Co

Young, W., Hwang, K., McDonald, S., \& Oates, C. J., 2010. Sustainable consumption: Green consumer behavior when purchasing products. Sustainable Development, 18(1): 20-31.

Youssef, A.B. \& Lahmandi-Ayed, R. 2008. Eco-labelling, competition and environment: Endogenization of labelling criteria. Environmental and Resource Economics, Springer, 41(2), pp.133-154. . 